\title{
Simulating or prescribing the influence of tides on the Amundsen Sea ice shelves
}

\author{
Nicolas C. Jourdain ${ }^{\mathrm{a}}$, Jean-Marc Molines ${ }^{\mathrm{a}}$, Julien Le Sommer ${ }^{\mathrm{a}}$, Pierre \\ Mathiot $^{\mathrm{b}}$, Jérôme Chanut ${ }^{\mathrm{c}}$, Casimir de Lavergne ${ }^{\mathrm{e}}$, Gurvan Madec ${ }^{\mathrm{d}}$ \\ ${ }^{a}$ Univ. Grenoble Alpes/CNRS/IRD/G-INP, IGE, Grenoble, France. \\ ${ }^{b}$ Met Office, Exeter, United Kingdom. \\ ${ }^{c}$ Mercator Ocean, Ramonville Saint Agne, France. \\ ${ }^{d}$ Sorbonne Universités (University Pierre et Marie Curie Paris 6)-CNRS-IRD-MNHN, \\ LOCEAN Laboratory, Paris, France. \\ ${ }^{e}$ University of New South Wales, Sydney, Australia.
}

\begin{abstract}
The representation of tides in regional ocean simulations of the Amundsen Sea enhances ice-shelf melting, with weakest effects for Pine Island and Thwaites $(<+10 \%)$ and strongest effects for Dotson, Cosgrove and Abbot $(>+30 \%)$. Tides increase vertical mixing throughout the water column along the continental shelf break. Diurnal tides induce topographically trapped vorticity waves along the continental shelf break, likely underpinning the tidal rectification (residual circulation) simulated in the Dotson-Getz Trough. However, the primary effect by which tides affect ice-shelf melting is the increase of ice/ocean exchanges, rather than the modification of water masses on the continental shelf. Tide-induced velocities strengthen turbulent heat fluxes at the ice/ocean interface, thereby increasing melt rates. Approximately a third of this effect is counterbalanced by the resulting release of cold melt water that reduces melt downstream along the meltwater flow. The relatively weak tide-induced melting underneath Pine Island and Thwaites could be partly related to their particularly thick water column, which limits the presence of quarter wavelength tidal resonance. No sensitivity to the position of Pine Island and Thwaites with respect to the $\mathrm{M}_{2}$ critical latitude is found. We refine and evaluate existing methodologies to prescribe the effect of tides on ice-shelf melt rates in ocean models that do not explicitely
\end{abstract}

Email address: nicolas.jourdain@univ-grenoble-alpes.fr (Nicolas C. Jourdain) 
include tidal forcing. The best results are obtained by prescribing spatiallydependent tidal top-boundary-layer velocities in the melt equations. These velocities can be approximated as a linear function of existing barotropic tidal solutions. A correction factor needs to be applied to account for the additional melt-induced circulation associated with tides and to reproduce the relative importance of dynamical and thermodynamical processes.

Keywords: Amundsen Sea, tides, ice shelf melt, ice shelf cavity, NEMO, Pine Island, Thwaites

\section{Introduction}

The interactions between the Southern Ocean and the Antarctic Ice Sheet remain poorly understood and simulated in spite of their importance for the ice sheet stability and associated global sea level rise (e.g., Jacobs et al., 2012; Asay-Davis et al., 2017; Turner et al., 2017). Part of the difficulty in simulating oceanic melt rates lies in the absence or poor representation of tides in the ocean models that are used for climate projections (e.g., Dinniman et al., 2016). Ice shelf cavities are usually represented in barotropic tide models (e.g., Padman et al., 2002; Carrère et al., 2012), but with no thermodynamical ice/ocean interactions. Several regional ocean models resolving the primitive equations and enabling thermodynamical ice/ocean interactions have been used to estimate tide-induced melting (e.g., Makinson et al., 2011; Mueller et al., 2012, 2018; Galton-Fenzi et al., 2012; Robertson, 2013; Mack et al., 2017). This was done by imposing the solution of one of the aforementioned barotropic tide models at the regional model lateral boundaries. However, these studies were limited to individual ice shelves and their close vicinity, and some did not account for variable atmospheric forcing. Several Ocean General Circulation Models (OGCMs) have the capability to represent aspects of the tidal signal in global ocean simulations (e.g., Savage et al., 2017; Stewart et al., 2018) but some processes are missing (see below), and so far, tides have not been used in OGCMs that represent ocean/ice-shelf interactions. In fact, most OGCMs or large-extent ocean regional models that include thermodynamical ocean/ice-shelf interactions rely on parameterizations to account for melting modulation by tides (see section 2), yet an assessment of these parameterizations is lacking.

In their review of tidal effects on ice sheets, Padman et al. (2018) distinguish tidal processes occurring seaward of the ice shelf, such as tidal vertical 
mixing and residual currents, from those directly affecting heat exchanges at the ocean/ice-shelf interface. Tidal vertical mixing is caused by (i) the vertical shear as barotropic tidal currents rub upon the seafloor (in particular in shallow areas where these currents tend to be relatively swift); and by (ii) the breaking of internal tidal waves (also called baroclinic tides or internal tides) generated by the interaction of barotropic tidal currents with steep topography. Internal tides freely propagate equatorward of a critical latitude at which the tidal frequency equals the inertial frequency. Critical latitudes are $74.5^{\circ}$ for $\mathrm{M}_{2}$ (principal lunar, semi-diurnal), $85.7^{\circ}$ for $\mathrm{S}_{2}$ (principal solar, semi-diurnal), and near 27 to $30^{\circ}$ for diurnal constituents dominated by $\mathrm{O}_{1}$ (principal lunar declinational) and $\mathrm{K}_{1}$ (luni-solar declinational) (e.g., Cartwright, 1977; Furevik and Foldvik, 1996). Poleward of the critical latitude, internal tides are trapped, i.e. they cannot propagate away from the topography where they are generated, and therefore, they only induce vertical mixing close to their generation site. Tidal vertical mixing has been suggested to mix the relatively cold ice-shelf melt water with the underlying and relatively warmer HSSW (High Salinity Shelf Water) in the Ross and Weddell Seas, thereby increasing ice-shelf melt (MacAyeal, 1984b; Scheduikat and Olbers, 1990; Makinson and Nicholls, 1999). Tides not only induce mixing but also generate a mean residual circulation through the Stokes drift and non-linear dynamics (Longuet-Higgins, 1969; Zimmerman, 1979). Residual transports of a few tenths of a Sverdrup $\left(1 \mathrm{~Sv}=10^{6} \mathrm{~m}^{3} \cdot \mathrm{s}^{-1}\right)$ affect heat and salt exchanges across the Ross and Weddell Sea continental shelves (Makinson and Nicholls, 1999; Padman et al., 2009; Wang et al., 2013), but are thought to be very small in all the other Antarctic Seas (Bessières et al., 2008). Heat and salt exchange across ice-shelf edges can also be significantly influenced by the tidal residual circulation (e.g., Makinson and Nicholls, 1999, for the Filchner-Ronne ice shelf).

Within ice shelf cavities, tides primarily affect ice/ocean interactions by increasing velocities and therefore turbulent exchanges along the ice base. This effect is relatively more important for large and cold cavities, such as Ross and Filchner-Ronne, where tidal currents can be significantly stronger than buoyancy-driven currents (e.g. MacAyeal, 1984a; Padman et al., 2003; Makinson et al., 2011), in contrast to other Antarctic ice shelves (e.g., Hemer et al., 2006; Robertson, 2013). Finally, the extra melting caused by tides induces an additional buoyancy-driven residual circulation, which in turn increases ice-shelf melting (MacAyeal, 1984b; Makinson and Nicholls, 1999). Estimating the relative importance of each of these tidal processes is a pre- 
requisite for better prescribing or parameterizing the effect of tides on ice shelf cavities.

While some models have the capability to explicitly simulate tides, prescribing or parameterizing their effects can be desirable for a range of applications. First, parameterizing their effects obviates the need for filtering model outputs for diagnostics over periods shorter than a few months (which has to be done to avoid aliasing if an explicit representation of tides is used). Second, even in OGCMs capable of representing tides, several processes such as loading and self-attraction are sometimes not accounted for (by contrast with some barotropic tide models). Finally, vertical mixing due to internal tides is usually not adequately simulated because ocean models do not resolve the cascade of energy conducive to the breaking of internal tides (Müller, 2013), and spurious diapycnal mixing can be caused by internal tides in level-coordinate models (Leclair and Madec, 2011). Several kinds of tidal mixing parameterization have been proposed so far for three-dimensional ocean models. Some of them enhance vertical diffusivity to account for the dissipation of barotropic (Lee et al., 2006; Holloway and Proshutinsky, 2007) or baroclinic (Simmons et al., 2004; Olbers and Eden, 2013) tides. It is also possible to parameterize the effect of residual tidal currents in a three-dimensional ocean model by adding velocities from the solution of a barotropic tidal model to the Eulerian velocities used in the equations of tracer advection (Bessières et al., 2008). So far, most modelling studies dedicated to ice-shelf/ocean interactions have, instead, parameterized the influence of tides within the formulation of the ice/ocean heat and salt fluxes in the top boundary layer of ice shelf cavities (Timmermann et al., 2002; Jenkins et al., 2010; Hattermann et al., 2014; Asay-Davis et al., 2016).

In this paper, we focus on the Amundsen Sea Embayment where the relatively warm ocean has a high potential to trigger marine ice sheet instabilities (e.g., Weertman, 1974; Schoof, 2007; Durand et al., 2009; Favier et al., 2014; Joughin et al., 2014; Mouginot et al., 2014), and where melt rates therefore need to be accurately simulated. In the Amundsen Sea, relatively warm Circumpolar Deep Water (CDW) penetrates into the ice shelf cavities, leading to the highest melt rates in Antarctica (e.g., Jacobs et al., 2012; Turner et al., 2017). As a consequence, the melt-induced circulation is particularly strong within ice-shelf cavities and in their vicinity (e.g., Jenkins, 1999; Dutrieux et al., 2014; Jourdain et al., 2017). As tides are also weaker than in the Ross and Weddell Seas (e.g., Padman et al., 2018), their effect on the Amundsen Sea circulation and ice shelf melt is often neglected. The inclusion of tides in 
an ocean model nonetheless indicated a significant increase in melt rates underneath some ice shelves, by $15 \%$ and $52 \%$ for Getz and Dotson ice shelves respectively (Robertson, 2013, , hereafter R2013). By contrast, R2013 did not find a strong effect on melt rates beneath Pine Island ice shelf (see ice shelf locations in Fig. 1). R2013 argued that the small effect of tides on Pine Island was due to its location poleward of the $\mathrm{M}_{2}$ critical latitude (red line in Fig. 1), inducing a more vertically uniform tidal flow and therefore weaker tidal currents near the ice shelf base. Here we propose a new estimation of tide-induced ice-shelf melting in the Amundsen Sea sector, accounting for synoptic and seasonal atmosphere and sea ice variability, and considering a large regional domain in order to analyze tidal processes both seaward and underneath ice shelves. We identify the most important impacts of tides on ice shelf melting in our simulations, and use this as a basis for evaluating and improving methods to prescribe the effects of tides in an ocean model (e.g., OGCM) that would not simulate them explicitly.

\section{Model experiments}

We make use of NEMO-3.6 (Nucleus for European Modelling of the Ocean; Madec and NEMO-team, 2016) that includes the ocean model OPA (Océan Parallélisé) and the Louvain-la-Neuve sea-ice model LIM-3.6 (Rousset et al., 2015) with a single ice category. We use the same AMU12.L75 regional configuration as Jourdain et al. (2017), with z-coordinates and an isotropic horizontal resolution of $\sim 3 \mathrm{~km}$ along the continental shelf break, thus resolving the first few vertical normal modes of internal tides. Our setup includes a split-explicit free surface formulation and a representation of ice-shelf cavities (Mathiot et al., 2017). The depth of the ocean/ice-shelf interface is calculated through the free surface formulation and fluctuates about the hydrostatic equilibrium position of ice within a reference ocean density profile. It is thus assumed that the ice flexural rigidity does not affect vertical motions of the ice/ocean interface. In our configuration, we assume a constant top-boundary-layer (TBL) thickness of $20 \mathrm{~m}$ and the heat flux through the TBL is expressed as in McPhee et al. (2008) and Jenkins et al. (2010):

$$
Q=\rho_{w} c_{p w} \Gamma_{\mathrm{T}} u_{\star}\left(T_{\mathrm{TBL}}-T_{f}\right)
$$

where $\Gamma_{\mathrm{T}}$ is a constant and uniform heat exchange coefficient, $u_{\star}$ the friction velocity, $\rho_{w}$ and $c_{p w}$ the density and heat capacity of sea water, and $\left(T_{\mathrm{TBL}}-T_{f}\right)$ 
is the difference between the TBL temperature and the freezing point at the ice draft depth. A similar expression is used for salinity. Simulated temperatures, salinities and velocities are averaged over the imposed TBL thickness to calculate the heat flux in Eq. (1) or in the equivalent expression for salinity as in Losch (2008).

All the experiments used in this paper are summarized in Tab. 1. To assess the representation of tides in our regional model configuration and to describe the characteristics of barotropic tides, we first run a pseudobarotropic simulation (referred to as BTP-07) in which the sea ice model is switched off, heat fluxes are set to zero at the ocean/ice-shelf interface, no atmospheric forcing is used, and lateral boundaries other than tidal constituents are set to zero velocities, with constant and uniform temperature and salinity profiles (equal to the domain-mean initial state values), in a similar way as Maraldi et al. (2013) and Mueller et al. (2012, 2018). The only external forcing consists of the amplitude and phase of seven tidal constituents $\left(\mathrm{M}_{2}, \mathrm{~S}_{2}, \mathrm{~N}_{2}, \mathrm{~K}_{1}, \mathrm{O}_{1}, \mathrm{Q}_{1}, \mathrm{M}_{4}\right)$, which are used as lateral boundary conditions for sea surface height and barotropic velocities. It is therefore assumed that the tidal signal is forced remotely, and that the gravitational forcing within the regional domain is negligible. The tidal constituents used as lateral boundary conditions are interpolated from the global Finite Element Solution FES2012 (Carrère et al., 2012; Lyard et al., 2006). The latter comes from the resolution of the tidal barotropic equations in the spectral domain with assimilation of long-term altimetry data. To compare our results to an independent tide dataset, we also use the CircumAntarctic Tidal Simulation CATS2008, which is an inverse model that assimilates altimetry data and in-situ tide records (updated version of Padman et al., 2002, https://www.esr.org/research/polar-tide-models/ list-of-polar-tide-models/cats2008). Both CATS2008 and a former version of FES were found to be relatively accurate near Dotson ice shelf despite the lack of assimilated data in the Amundsen Sea (McMillan et al., 2011). Our harmonic analyses are done after 2 years of spin-up, and are based on 15-minute samples analyzed over a 190-day window. With these characteristics, our harmonic analyses can accurately separate at least 7 tidal constituents.

The second set of experiments is designed to represent more realistic conditions, with fully-coupled sea-ice and thermodynamically-coupled iceshelf cavities. Lateral boundaries (temperature, salinity, velocities) are from the global $0.25^{\circ}$ simulation described by Spence et al. (2014). Importantly, 
that global simulation does not represent tides. Both the global simulation and the regional experiments are forced by atmospheric fields from version 2 of the Coordinated Ocean-ice Reference Experiments (CORE-2) Normal Year Forcing (NYF) (Griffies et al., 2009; Large and Yeager, 2009). The reference experiment (REF), which includes no tidal constituents, is the one described and evaluated with respect to CTD, ice-shelf melt rates, and sea ice cover by Jourdain et al. (2017). The mean barotropic circulation in REF is shown in Fig. 1. We then ran three additional simulations accounting for one, four, and 18 tidal constituents. The latter are imposed through lateral boundary conditions as for BTP-07, but on top of other oceanic boundary conditions from the global $0.25^{\circ}$ simulation. The TIDE-M2 simulation only includes the $\mathrm{M}_{2}$ tidal constituent because its importance was emphasized in R2013. The TIDE-04 simulation additionally includes $\mathrm{S}_{2}, \mathrm{~K}_{1}$, and $\mathrm{O}_{1}$. Finally, the TIDE-18 simulation includes the four aforementioned constituents and $\mathrm{N}_{2}$, $\mathrm{K}_{2}, \mathrm{P}_{1}, \mathrm{Q}_{1}, \mathrm{~N}_{1}, 2 \mathrm{~N}_{2}, \mu_{2}, \nu_{2}, \mathrm{~L}_{2}, \mathrm{~T}_{2}, \mathrm{M}_{4}$, Mf, Mm and Mtm (e.g. Schureman, 1958).

A third set of experiments is designed to propose a method to prescribe the effect of tides on ice shelf melt. It is based on our most realistic configuration (i.e. with stratification, sea ice, atmospheric forcing), but has no tides prescribed at its boundaries. A first possibility to account for non-resolved tides in (1) is to use a velocity-independent formulation of $Q$ :

$$
Q=\rho_{w} c_{p w} \gamma_{\text {то }}\left(T_{\mathrm{TBL}}-T_{f}\right)
$$

where $\gamma_{\text {то }}$ is a constant referred to as heat exchange velocity. The $\gamma_{\text {то }}$ value can be chosen to represent non-resolved tidal velocites in cavities where tides dominate the circulation (Timmermann et al., 2002), and can also represent the poorly captured buoyancy-driven circulation in coarse-resolution models. However, a majority of recent simulations have preferred a velocitydependent formulation of ice-shelf/ocean heat fluxes (Eq. 1), because it better accounts for non-uniform circulation and melt-circulation feedbacks (Dansereau et al., 2014; Asay-Davis et al., 2017; Donat-Magnin et al., 2017). We therefore opt for another method in which the expression of $u_{\star}$ in (1) is modified as follows:

$$
u_{\star}=\sqrt{C_{d}\left(u_{\mathrm{TBL}}^{2}+u_{\mathrm{tide}}^{2}\right)}
$$

where $C_{d}$ is the drag coefficient, $u_{\mathrm{TBL}}$ the TBL velocity simulated by NEMO (averaged within the imposed TBL thickness), and $u_{\text {tide }}$ is a prescribed "tidal TBL velocity" (e.g. Jenkins et al., 2010; Hattermann et al., 2014; Asay-Davis 
et al., 2016). To our knowledge, such parameterization of tidal effects has always been used at a single point or with a uniform tidal TBL velocity, although Jenkins et al. (2010) noted that such velocity would ideally be a spatially varying quantity. It is presently unclear to what extent such prescription of mean-square tidal TBL velocity adequately accounts for the various processes involved in the overall interactions between tides and iceshelves. Here we assess three different definitions of the tidal TBL velocity: uniform velocity for all the ice shelves in the domain (Utide-UNIF), uniform velocity under each ice shelf, but with a value specific to each ice shelf (UtidePERISF), and 2-dimensional local velocities (Utide(x,y)). The methods used to calculate these prescribed velocities are discussed along with the results.

All the analyses performed on the second and third sets of experiments are done after a spin up of 6 years, which is sufficient to reach a steady state (Jourdain et al., 2017). We analyze yearly averages over the $7^{\text {th }}$ year. Oneyear average is enough to avoid any significant aliasing by the modulation of the four main tidal harmonics by the other harmonics represented here (as indicated by Tab. 4-7 of Müller, 2013).

\section{Results}

\subsection{Harmonic decomposition of barotropic tides}

We start with a description of the main characteristics of barotropic tides in the Amundsen Sea. A Sea Surface Height ( $\mathrm{SSH}$ ) harmonic analysis of the BTP-07 simulation (Fig. 2) indicates a stronger amplitude for the diurnal $\left(\mathrm{O}_{1}\right.$ and $\left.\mathrm{K}_{1}\right)$ than for the semi-diurnal $\left(\mathrm{M}_{2}, \mathrm{~S}_{2}, \mathrm{~N}_{2}\right)$ harmonics in the Amundsen Sea (Fig. 2). The $\mathrm{M}_{4}$ constituent, resulting from an interaction of $\mathrm{M}_{2}$ with itself, is significantly weaker than the other six constituents. The diurnal constituents generate topographically trapped vorticity waves along the continental shelf break (stronger amplitude and closed cotidal lines in Fig. 2a,b), as previously described for other locations poleward of the diurnal critical latitudes (e.g. Middleton et al., 1987; Padman and Kottmeier, 2000; Padman et al., 2003). The semi-diurnal constituents experience a stronger signal in the cavities than on the continental shelf seaward of the ice fronts (Fig. 2c,d,e), which is reminiscent of tide resonance in semi-enclosed bays. Such resonance can occur for bays of characteristic size close to the tidal quarter wavelength which can be estimated as $\sqrt{g H} / \nu_{\text {tide }}$, where $g$ is the gravity acceleration, $H$ the water column thickness, and $\nu_{\text {tide }}$ the tidal frequency (Fig. 3). The qualitative match between the semi-diurnal quarter 
wave lengths and the cavity sizes (Fig. 3b) supports the similarity between the resonance in semi-enclosed bays and the resonance in ice-shelf cavities. For diurnal constituents, quarter wave lengths are longer than most typical ice-shelf sizes, so that cavities appear less resonant. There is weak resonance in Thwaites and in the core of Pine Island: the cavities are deep and therefore present a quarter wave length much longer than the cavity size. Finally, considering the entire Amundsen Sea Embayment in Fig. 3, the continental shelf appears too narrow or too deep to favour a widespread resonance of diurnal and semi-diurnal tides in this region.

The harmonic analysis of barotropic velocities in the BTP-07 simulation indicates strong amplitude along the continental shelf break for the diurnal constituents (up to $25 \mathrm{~cm} . \mathrm{s}^{-1}$ in Fig. 4a,b). These patterns are consistent with the aforementioned topographically trapped vorticity waves and are expected to induce vertical mixing as they dissipate locally. For most constituents, strong barotropic velocities are also generated within ice shelf cavities, with the exception of Thwaites and the main trunk of Pine Island cavity (Fig. 4), likely because of the aforementioned reduced quarter wavelength resonance. Such strong tidal velocities under the ice shelves are expected to increase TBL velocities, and therefore melt rates.

The tidal residual circulation is now estimated using the same methodology as Bessières et al. (2008), i.e. through the annual mean barotropic stream function (Fig. 5). The main feature is a strengthening of the Antarctic Slope Current (westward jet along the continental shelf break, e.g. Heywood et al., 1998; Mathiot et al., 2011) by up to $0.8 \mathrm{~Sv}$ (maximum barotropic stream function difference between 2 points). Locally, the residual circulation can be more important than the background ocean circulation, e.g. 0.70 Sv residual transport through the green section in Fig. 5 vs $0.49 \mathrm{~Sv}$ in the REF simulation (Fig. 1). This effect is locally important, but remains small compared to the total barotropic transport by the Slope Current which is approximately $12 \mathrm{~Sv}$ along the entire slope of the continental shelf (e.g., $0.12 \mathrm{~Sv}$ residual in Fig. 5 vs $11.7 \mathrm{~Sv}$ through the cyan section in Fig. 1a). There is also a southward residual flow on the eastern flank of Dotson-Getz Trough. It reach approximately $0.2 \mathrm{~Sv}$ near the continental shelf break, $0.17 \mathrm{~Sv}$ through the magenta section, and gradually decreases to zero near the ice shelves. The associated transport has a similar magnitude as the transport in the absence of tides at this location (e.g., 0.13 Sv through the magenta section in Fig. 1b). These residual circulations were not found in Bessières et al. (2008), possibly due to their different set-up (e.g. their coarser horizontal resolution). 
Underneath most ice shelves, the residual tidal circulation is typically a few $\mathrm{mSV}$, which represents only a few percent of the circulation in the presence of ice shelf melt (Tab. 2). This effect is slightly stronger for Getz and Abbot, where the residual tidal circulation reaches $\sim 20 \mathrm{mSv}$, representing $\sim 10 \%$ of the circulation in the presence of ice shelf melt (Tab. 2).

We now compare the tide characteristics in the NEMO pseudo-barotropic simulation to the barotropic tide models, in order to assess NEMO's ability to rebuild the tidal signals from the lateral boundary conditions. Overall, there is a fair agreement between the SSH harmonics from NEMO and those from FES2012 and CATS2008, both in terms of phase and amplitude (Fig. S1S3). An exception is the phase of $\mathrm{M}_{2}$ that is quite different between NEMO and the tide models, but also between FES2012 and CATS2008. A possible explanation is a particularly strong sensitivity to the different bathymetries used in these models near the critical latitude. The amplitude of diurnal SSH harmonics is slightly weaker in NEMO than in FES2012 and CATS2008 (Fig. S1ab-S3ab), which could be related to the absence of direct tide influence (gravitational potential) on the water mass located within our simulation domain. It is unclear why the resonance of semi-diurnal constituents within the ice shelf cavities is significantly less prominent in FES2012 and CATS2008 than in NEMO (Fig. S1cde-S3cde). The harmonics of barotropic velocities in NEMO have a pattern that better matches CATS2008 than FES2012, but the maximum velocity amplitude along the continental shelf break and within ice-shelf cavities in NEMO is more similar to FES2012 ( $\sim 25 \mathrm{~cm} . \mathrm{s}^{-1}$, not shown) than to CATS2008 ( 16 cm.s ${ }^{-1}$, not shown).

\subsection{Impact of tides on ice-shelf melt}

R2013 has been the only study so far to estimate the effects of tides on iceshelf melt in the Amundsen Sea sector. Besides a different ocean model used, that study did not account for sea ice or for variability in the atmospheric forcing. We therefore revisit the influence of tides in this sector with a more realistic model set-up including sea ice and an atmosphere that varies at seasonal and synoptic scales. As R2013 emphasized the importance of the presence of the $\mathrm{M}_{2}$ critical latitude near the ice shelves of the Amundsen Sea, we first run a simulation that is only forced by $\mathrm{M}_{2}$. Then, we add three additional constituents, $\mathrm{K}_{1}, \mathrm{O}_{1}$, and $\mathrm{S}_{2}$, which have stronger amplitudes than $\mathrm{M}_{2}$, to get the same set of four harmonics as used by R2013. Finally, we use a total of 18 harmonics (see section 2) to estimate the influence of a more complete tidal signal on melt rates. 
The effect of 18 tidal harmonics is shown in Fig. 6a. Tides generally increase melt rates (Tab. 3), although a weak decrease is found at a few locations, mostly in the Getz cavity. However, even with 18 tidal constituents, the increase is negligible for Pine Island (Tab. 3) and small for Thwaites $(+7.8 \%)$, which is consistent with the weak tidal amplitude in these two cavities. By contrast, the relative increase is larger than $30 \%$ for Dotson, Cosgrove and Abbot. These results have to be considered carefully because of the high uncertainty on the bathymetry under these ice shelves. Using four tidal constituents instead of 18 induces errors below $6 \%$, so restricting a tidal analysis to four constituents as in R2013 seems very reasonable. Tide-induced melt is generally not located near grounding lines (Fig. 6a), probably because tidal currents often become weak in the shallowest parts of small cavities.

Our results with four constituents are in qualitative agreement with R2013 on the relative importance of tides for three different cavities, although we find slightly weaker effects. R2013 found that tides were responsible for moderate change in the Getz cavity $\left(+24 \mathrm{Gt}_{\mathrm{yr}}{ }^{-1},+15 \%\right)$, stronger change in Dotson cavity $\left(+11 \mathrm{Gt}_{\mathrm{yr}}{ }^{-1},+52 \%\right)$, and little change in Pine Island cavity $\left(-2\right.$ Gt.yr $\left.{ }^{-1},-3 \%\right)$. R2013 also emphasized the importance of $\mathrm{M}_{2}$ and the associated critical latitude. Our simulation in which only $\mathrm{M}_{2}$ is represented indicates that this constituent only accounts for a limited part of the tidal influence on melt rates. This was expected from the dominance of diurnal tides and of S2 over M2 revealed by the pseudo-barotropic simulations. Further, we repeated R2013's experiment where the latitudes were shifted by $1^{\circ} \mathrm{S}$ (i.e. bathymetry and ice drafts are shifted by $1^{\circ} \mathrm{N}$ ). We ran shifted-latitude experiments with and without tides to isolate the effect on the geostrophic circulation from the critical latitude effects. In the absence of tides, shifting latitudes enhances mean melt rates in all the cavities, but the increase is weaker than $2.5 \%$ everywhere (Fig. $7 \mathrm{a}$ ). In the presence of tides, shifting latitudes affect melt rates by less than $1 \%$ in all the cavities (Fig. 7b). This implies that the $\mathrm{M}_{2}$ critical latitude is of limited importance to the ice-shelf melting in this region. A possible explanation for the opposite conclusion of R2013 is that our atmospheric forcing varies at synoptic and seasonal scales, which may lead to a large variability of the effective critical latitude (accounting for the ocean relative vorticity). This result is reminiscent of Richet et al. (2017) who analyzed simulations with weakened critical latitude effects on tidal energy dissipation in the presence of a background ocean circulation. 
We now look further into the physical mechanisms through which tides affect ice-shelf melt rates. Neglecting heat diffusion in ice (which yields no more than 10-20\% error according to Dinniman et al. (2016) and Arzeno et al. (2014)), the melt rate $m$ (in meters of ice per second) can be approximated as:

$$
\rho_{i} m \simeq \rho_{w} c_{p w} \gamma_{\mathrm{T}}\left(T_{\mathrm{TBL}}-T_{f}\right) / L_{f}
$$

where $\rho_{i}$ is the ice density, $L_{f}$ the latent heat associated with melting/freezing, $\gamma_{\mathrm{T}}=\Gamma_{\mathrm{T}} u \star$, and other variables have been introduced in (1). Expressing $\gamma_{\mathrm{T}}$ in the presence of explicit tides as $\left(\gamma_{\mathrm{T}}\right)_{\text {tide }}=\left(\gamma_{\mathrm{T}}\right)_{\text {no tide }}+\Delta \gamma_{\mathrm{T}}$ in (4), and similarly for the thermal forcing, we can define a dynamical/thermodynamical decomposition that explains the differences in melt rates between the simulations with and without tides:

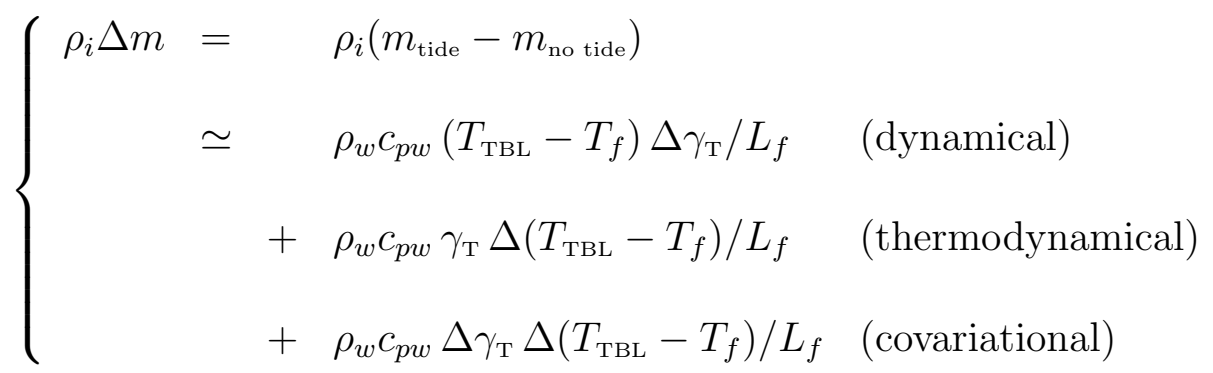

The decomposition for the simulation with 18 tidal harmonics indicates that tidal velocities in the TBL of ice-shelf cavities are the main driver of increased melt rates (the dynamical term dominates in Fig. 6). This dynamical term includes the mean effect of tidal velocities but also the effect of the additional buoyancy-driven circulation caused by tide-induced melting. About a third of the dynamical component is compensated by the thermodynamical and covariational components (Fig. 6c,d). The negative covariational component can be understood as a decrease of thermal forcing (through latent heat and injection of water at the freezing point) occuring where and when the TBL velocities are increased. The thermodynamical component accounts for a tide-induced reduction of thermal forcing in the cavities. It could a priori either come from a tide-induced cooling on the continental shelf (resulting from increased vertical mixing or residual currents), from a non-local thermal effect of increased melt rates (the local part being in the covariational term), or from modified vertical mixing within ice shelf cavities (outside the TBL). Similar tide-induced reduction in thermal forcing was reported by Gwyther et al. (2016). Our simulations indicate locally increased vertical diffusivity 
$\left(K_{z}\right)$ in ice shelf cavities (Fig. 8), but this tends to bring heat from below and therefore increase temperatures in the TBL, whereas a decrease is found. We also find that subsurface $(200-1000 \mathrm{~m})$ temperatures over the continental shelf tend to get warmer when tides are included, by up to $0.15^{\circ} \mathrm{C}$ and $0.45^{\circ} \mathrm{C}$ in front of Abbot and Dotson-Getz respectively (not shown), which likely results from a combination of both increased vertical mixing associated with topographically-trapped vorticity waves (Fig. 8) and the tidal residual circulation depicted in Fig. 5. However, this coastal warming cannot explain the decreased thermal forcing within ice shelf cavities. We conclude that the negative thermal component is explained by non-local thermal effect related to the injection and transport of cold meltwater in the TBL.

The prominence of the dynamical component in our decomposition supports the concept of parameterizing the tides effect on melt rates through a prescribed tidal velocity, although the thermodynamical and covariational components are non negligible. Such parameterization is explored in the following sub-section.

\subsection{Prescribing the effect of tides}

We now attempt to represent the tidal influence on melt rates without explicitly representing tides in our simulations, but rather by prescribing a "tidal TBL velocity" $u_{\text {tide }}(x, y)$ in (3). Ideally $u_{\text {tide }}$ would be deduced from a tidal model such as FES2012 or CATS2008, but we start with a proof of concept, assuming that the tidal influence on TBL velocities is perfectly known, and trying to reproduce the effect of tides on melt rates through the use of (3) in the melt equations of NEMO. A first challenge is to deduce $u_{\text {tide }}(x, y)$ from the simulation with explicit tides. A first possibility is to define $u_{\text {tide }}(x, y)$ as the local time-RMS difference between TBL velocities with and without tides:

$$
u_{\text {tide }}(x, y)=\sqrt{\overline{u_{\mathrm{TBL}, \mathrm{TIDE} 18}^{2}(x, y)}-\overline{u_{\mathrm{TBL}, \mathrm{REF}}^{2}(x, y)}}
$$

where $u$ are velocity amplitudes and overbars are 1-year averages (exact calculation of mean square TBL velocities during the simulations). Such definition leads to an overestimation of melt fluxes by $63 \mathrm{Gt}_{\mathrm{tar}}{ }^{-1}$, i.e. by $68 \%$ (Fig. 9a). This strong overestimation is due to the melt-induced circulation that is included in our calculation of $u_{\text {tide }}(x, y)$. Indeed, by prescribing $u_{\text {tide }}(x, y)$ in (3), we increase melt rates, which creates an additional meltinduced circulation, which, in turns, further amplifies melt rates. In other 
words, this definition of $u_{\text {tide }}(x, y)$ leads to double the feedback of the meltinduced circulation on melt rates.

A better way to estimate $u_{\text {tide }}(x, y)$ is to perform a harmonic analysis on TBL velocities in our realistic simulation with tides. As in the pseudobarotropic case, we analyze 15-minute samples over a 190-day window, and extract the seven main harmonics $k$, i.e. the amplitude $\left(u_{k}, v_{k}\right)$ and phase $\left(\phi_{k}, \psi_{k}\right)$ of zonal and meridional TBL velocities. From this, we reconstruct the RMS tidal TBL velocity as:

$u_{\text {tide }}^{2}(x, y)={\overline{\left(\sum_{k=1}^{7} u_{k}(x, y) \cos \left(\omega_{k} t+\phi_{k}(x, y)\right)\right)^{2}+\left(\sum_{k=1}^{7} v_{k}(x, y) \cos \left(\omega_{k} t+\psi_{k}(x, y)\right)\right)^{2}}}^{190 d}$

where $\omega_{k}$ is the angular frequency of harmonic $k$. This definition of $u_{\text {tide }}(x, y)$ gives weaker velocities than the previous definition (see last columns in Tab. 3), indicating that tidal currents create a residual melt-induced circulation that does not appear in the harmonic analysis. Such residual circulation is specific to ice shelf cavities and is distinct from the one due to the Stokes drift and non-linear dynamics (see Introduction). In terms of melt rates, the bias is reduced by half compared to the previous definition, with an overestimation by $31 \mathrm{Gt} . \mathrm{yr}^{-1}$, i.e. $34 \%$ (Fig. 9b). The remaining overestimation suggests that there is also a melt-induced circulation varying at tidal frequencies. The latter is included in our calculation of $u_{\text {tide }}(x, y)$ so that the feedback of the melt-induced circulation to melt rates is still overestimated.

To get rid of the overestimated melt-induced circulation at tidal frequencies, we multiply $u_{\text {tide }}(x, y)$ by a correction factor $\alpha$, i.e. the simulated value of $u_{\star}$ is calculated as:

$$
u_{\star}(x, y)=\sqrt{C_{d}\left(u_{\mathrm{TBL}}^{2}(x, y)+\alpha^{2} u_{\text {tide }}^{2}(x, y)\right)}
$$

where $u_{\mathrm{Tв}}$ is the TBL velocity resolved by the ocean model. Empirically, we find that $\alpha=0.777$ reduces the melt bias to nearly zero. Applying the decomposition defined in (5) to the case of prescribed $\alpha u_{\text {tide }}(x, y)$, we find that the dynamical/thermodynamical/covariational contributions are 148/$34 /-23$ Gt. $\mathrm{yr}^{-1}$ respectively versus 148/-31/-26 Gt. $\mathrm{yr}^{-1}$ in the simulation with explicit tides (Fig. 6). This shows that this method correctly replicates the effect of tides on melt rates. This result also supports the interpretation that tides mostly affect ice shelf melting through tidal velocities along the ice draft and subsequent turbulent exchange rather than through residual 
circulation or tidal mixing farther from the ice shelf base. Prescribed tidal TBL velocities have no marked effect on $K_{z}$ in ice-shelf cavities and along the continental shelf break (Fig. 8d), which indicates that tide-induced changes in $K_{z}$ (Fig. 8c) are mostly related to tidal currents and not to the melt-induced circulation. It also confirms the negligible effect of tidal vertical mixing on melt rates in our simulations.

So far, the studies parameterizing the effect of tides have prescribed uniform tidal velocities (e.g. Hattermann et al., 2014; Asay-Davis et al., 2016). We therefore evaluate this approach by prescribing uniform $u_{\text {tide }}$ obtained through an average of $u_{\text {tide }}(x, y)$ all over the domain $\left(3.5 \mathrm{~cm} . \mathrm{s}^{-1}\right)$ or for each individual ice shelf (values in the last column of Tab. 3). The bias is approximately 1.5 and 2 times larger with per-ice-shelf and domain-wide uniform velocities respectively than with spatially-dependent velocities (Fig. 9c,d). The strongest biases are found in the vicinity of deep grounding lines, particularly for Thwaites and Pine Island, where thermal forcing is high due to the presence of CDW, but where tides do not produce strong velocities (see subsection 3.2 and Mueller et al., 2012 and Gwyther et al., 2016). Given the sensitivity of the ice sheet dynamics to melting at the grounding line, we conclude that prescribing uniform tidal TBL velocities is best avoided.

As mentioned earlier, a tide parameterization would be more useful if it can be directly based on the barotropic velocities derived from tide models such as FES2012 or CATS2008. As shown in Fig. 10, $\alpha u_{\text {tide }}(x, y)$ is significantly correlated with $\left\langle U_{b t p}\right\rangle(x, y)$ calculated as in $(7)$ but with amplitude and phases related to the barotropic velocities in the pseudo-barotropic experiment (BTP-07) rather than the TBL velocites in the realistic experiment (TIDE-18). It is therefore a good approximation to define $\alpha u_{\text {tide }}(x, y)$ as a linear function of $\left\langle U_{b t p}\right\rangle(x, y)$ calculated from the output of a tide model.

In summary, we suggest the following method to parameterize the effect 


$$
\begin{cases}\gamma_{T}(x, y) & =\Gamma_{T} u_{\star}(x, y) \\ u_{\star}(x, y) & =\sqrt{C_{d}\left(u_{\mathrm{TBL}}^{2}(x, y)+\alpha^{2} u_{\mathrm{tide}}^{2}(x, y)\right)} \\ \alpha u_{\mathrm{tide}}(x, y) & =A_{0}\left\langle U_{b t p}\right\rangle(x, y)+U_{0} \\ \left\langle U_{b t p}\right\rangle^{2}(x, y) & =\left(\sum_{k} U_{k}(x, y) \cos \left(\omega_{k} t+\Phi_{k}(x, y)\right)\right)^{2}+\left(\sum_{k} V_{k}(x, y) \cos \left(\omega_{k} t+\Psi_{k}(x, y)\right)\right)^{2}\end{cases}
$$

in which $u_{\mathrm{TBL}}$ is the ocean model solution, $\left(U_{k}, V_{k}\right)$ and $\left(\Phi_{k}, \Psi_{k}\right)$ are the amplitudes and phases of zonal and meridional barotropic velocities provided by the tide model for each harmonic of angular frequency $\omega_{k}$, and $\Gamma_{\mathrm{T}}, C_{d}, \alpha, A_{0}$, and $U_{0}$ are constant scalars with values summarized in Tab. 4. The overline represents an average over a period that is long enough to correctly sample the interaction between harmonics (e.g. 6 months for 7 harmonics). The parameters $A_{0}$ and $U_{0}$ account for the shape of the vertical velocity profile in ice shelf cavities (their values are shown in Fig. 10). A non-zero $U_{0}$ ensures a background heat transfer due to molecular diffusivity in the case of zero TBL velocity and zero tidal velocity, although we obtain $U_{0}$ from an empirical fit with no knowledge of the role of molecular diffusivity. Gwyther et al. (2016) estimated that $u_{\star}$ should have a minimum value of approximately $2.0 \times 10^{-5} \mathrm{~m} . \mathrm{s}^{-1}$ due to molecular diffusion, which would be equivalent to $U_{0}=6.3 \times 10^{-4} \mathrm{~m} . \mathrm{s}^{-1}$ in (9) i.e. $\sim 5$ times less than our value.

\section{Discussion and Conclusion}

In this paper, we have undertaken harmonic analyses of pseudo-barotropic simulations to show that our regional model configuration is able to produce tides with similar characteristics as in the barotropic tide simulation imposed at the domain lateral boundaries. Diurnal tides induce topographically trapped vorticity waves along the continental shelf break in the vicinity of the Dotson-Getz Trough. This slightly strengthens vertical mixing in that area, and is likely responsible for the residual circulation of $0.2 \mathrm{~Sv}$ that flows southward on the eastern flank of the Dotson-Getz Trough. While diurnal tides have a larger amplitude than semi-diurnal tides over the Amundsen 
Sea continental shelf, semi-diurnal tides are found to resonate in the shallowest ice-shelf cavities, so that both diurnal and semi-diurnal tides produce strong velocities at the base of the ice shelves. Tides increase mean melt rates in all the simulated cavities of the Amundsen Sea, with weakest effects for Pine Island and Thwaites $(<+10 \%)$ and strongest effects for Dotson, Cosgrove and Abbot $(>+30 \%)$. There is a large uncertainty on these estimates, in particular because of the poorly known bathymetry underneath ice shelves, and recent studies have proposed alternative bathymetry datasets in the Amundsen Sea sector (Schaffer et al., 2016; Millan et al., 2017).

We suggest that the weak tide-induced melting underneath Pine Island and Thwaites is partly related to the particularly thick water column for these cavities, which makes resonant quarter wavelengths much larger than the cavity size and therefore limits the presence of tidal resonance. By contrast with Robertson (2013), we do not find a significant influence of the position of Pine Island and Thwaites with respect to the $\mathrm{M}_{2}$ critical latitude. The importance of tidal resonances suggests that the characteristics of tides may evolve in a warmer climate with thinner ice shelves and retreated grounding lines. Proximity to resonance is also affected by large uncertainties in the bathymetry underneath ice shelves (e.g., Schaffer et al., 2016; Millan et al., 2017).

A dynamical/thermodynamical decomposition for all the simulated ice shelves indicates that enhanced melting when tides are explicitly added is mostly due to tide-induced velocities in the top boundary layer that enhance heat fluxes at the ice/ocean interface. Approximately a third of this effect is counterbalanced by the resulting additional release of cold melt water. We also present evidence for a positive feedback whereby tide-induced circulation produces more melt, which strengthens the buoyancy-driven ocean circulation underneath ice shelves, in turn producing stronger melting. Such positive feedback was previously reported by Makinson et al. (2011) in the case of the Filchner-Ronne Ice Shelf. We find that tide-induced vertical mixing does not significantly affect melt rates. This result has to be taken cautiously because (1) our model resolution only allows the first few vertical normal modes of internal tides to be resolved, and (2) the simulated vertical mixing is inaccurate because the model is not able to explicitly represent internal wave breaking (and the energy cascade) associated with the resolved modes. These are, however, general caveats of large-scale ocean models, and the first few baroclinic modes still contain most of the energy of internal tides. 
As tides mostly affect simulated melt rates through increased velocities in the top boundary layer (TBL) of ice-shelf cavities, it is possible to prescribe their effect by including a "tidal TBL velocity" in the calculation of the friction/exchange velocity along the ice draft. In the Amundsen Sea, prescribing a spatially-uniform tidal TBL velocity leads to overestimated melt rates near deep grounding lines where the thermal forcing is high due to the presence of modified CDW, but where simulated tidal currents are weak. In the absence of spatially-distributed observations of tidal currents along the ice draft, we therefore recommend to derive spatially-varying tidal velocities from the outputs of tide models following Eq. (9). In our simulations, TBL velocities can be prescribed as $66 \%$ ( $A_{0}$ in Tab. 4 ) of the barotropic velocities from a tide model to account for the vertical profile due to the interaction with the ice draft and for the melt-induced circulation. Furthermore, if it was possible to observe spatially distributed currents underneath an ice shelf and to perform a harmonic analysis, we would still have to apply a correction factor of $\sim 0.777$ before prescribing the observed mean-square TBL velocity into the TBL equations of an ocean model. Indeed, tide-induced melting enhances observed TBL velocities, so that directly applying observed velocities would effectively apply these velocities twice, due to the feedback related to the buoyancy-driven ocean circulation.

The proposed methodology to represent the effects of tides on melt rates is not a standalone parameterization in the sense that it relies on a tide model. For example, our methodology would remain valid in a warmer ocean, with a different coastal circulation, but would not allow adapting the tide characteristics (e.g. resonance) for evolving cavity shapes (see Mueller et al., 2018) or when new bathymetry datasets become available. In this respect, the proposed methodology can be considered as bulk formula for the interface with barotropic tide models, in a similar way as the bulk formula used to calculate air-sea fluxes from atmospheric models or reanalyses. Relying on barotropic models specially developed for tides allows more accuracy in the tide solution (e.g. through data assimilation) and a higher level of complexity in the representation of tidal processes (e.g. self attraction and loading) compared to what is usually implemented in OGCMs.

We suggest that our methodology to prescribe tidal TBL velocities could be applied to other sectors of Antarctica, but with care with regards to two aspects. First, although vertical mixing and residual circulation near the continental shelf break have no major effects on ice-shelf melting in the Amundsen Sea, this may not be true elsewhere in Antarctica. For example, water 
masses in cold cavities such as Ross and Filchner-Ronne could hypothetically be more sensitive to the tide-induced exchanges across the continental shelf and ice-shelf front. Second, our parameterization includes a factor $\alpha$ to account for the buoyancy-driven TBL velocity associated with tide-induced melting. According to the theoretical considerations in Appendix C of Jourdain et al. (2017), this factor is likely non-uniform around Antarctica, and should depend on the background ocean density and on the depth at which tides enhance melt rates. We nonetheless suggest to use $\alpha<1$ everywhere, as buoyancy-driven circulation resulting from tide-induced melting is expected to occur in any ice shelf cavity. For example, such buoyancy-driven circulation was simulated under Filchner-Ronne by Makinson et al. (2011).

Our concluding remark is for melt rate parameterizations used in ice sheet models (see review in Asay-Davis et al., 2017). The methodology proposed in this paper to prescribe tides could be applied to these parameterizations in order to better distinguish melt-induced and tide-induced circulation. The background melt-induced circulation depends on the thermal forcing and makes melt rates proportional to the square thermal forcing (Holland et al., 2008). In contrast, tide-induced melt rates are expected to depend more linearly on the thermal forcing, although a weak non-linearity may also be expected due to the additional circulation induced by melting.

\section{Data availability}

The model version, customizations, and parameters used to run the eight main experiments presented in this paper are provided on http://doi.org/ 10.5281/zenodo.1067647. The output and forcing files are available on request.

\section{Acknowledgments}

This work was funded by the French National Research Agency (ANR) through the TROIS-AS (ANR-15-CE01-0005-01) project. NJ, JMM and JL are part of Labex OSUG@2020 (ANR10 LABX56). This work was granted access to the HPC resources of CINES under the allocations x2016016035 and c2016016066 made through GENCI. We thank Editor Sergey Danilov, as well as David Gwyther, Laurie Padman, and two other anonymous reviewers for their careful review of our manuscript. 


\section{References}

Arzeno, I. B., Beardsley, R. C., Limeburner, R., Owens, B., Padman, L., Springer, S. R., Stewart, C. L., Williams, M. J. M., 2014. Ocean variability contributing to basal melt rate near the ice front of Ross Ice Shelf, Antarctica. J. Geophys. Res. Oceans 119 (7), 4214-4233.

Asay-Davis, X. S., Cornford, S. L., Durand, G., Galton-Fenzi, B. K., Gladstone, R. M., Gudmundsson, G. H., Hattermann, T., Holland, D. M., Holland, D., Holland, P. R., et al., 2016. Experimental design for three interrelated Marine Ice-Sheet and Ocean Model Intercomparison Projects. Geoscientific Model Development 9, 2471-2497.

Asay-Davis, X. S., Jourdain, N. C., Nakayama, Y., 2017. Developments in Simulating and Parameterizing Interactions Between the Southern Ocean and the Antarctic Ice Sheet. Current Climate Change Reports 3 (4), 316329 .

Bessières, L., Madec, G., Lyard, F., 2008. Global tidal residual mean circulation: Does it affect a climate OGCM? Geophys. Res. Lett. 35 (3).

Carrère, L., Lyard, F., Cancet, M., Guillot, A., Roblou, L., 2012. FES2012: A new global tidal model taking advantage of nearly 20 years of altimetry. In: Proceedings of the "20 Years of Progress in Radar Altimetry" Symposium, Venice. pp. 1-20.

Cartwright, D. E., 1977. Oceanic tides. Reports on Progress in Physics 40 (6), 665.

Dansereau, V., Heimbach, P., Losch, M., 2014. Simulation of subice shelf melt rates in a general circulation model: Velocity-dependent transfer and the role of friction. J. Geophys. Res. 119 (3), 1765-1790.

Dinniman, M. S., Asay-Davis, X. S., Galton-Fenzi, B. K., Holland, P. R., Jenkins, A., Timmermann, R., 2016. Modeling ice shelf/ocean interaction in Antarctica: A review. Oceanography 29 (4), 144-153.

Donat-Magnin, M., Jourdain, N. C., Spence, P., Le Sommer, J., Gallée, H., Durand, G., 2017. Ice-Shelf Melt Response to Changing Winds and Glacier Dynamics in the Amundsen Sea Sector, Antarctica. J. Geophys. Res. 
Durand, G., Gagliardini, O., De Fleurian, B., Zwinger, T., Le Meur, E., 2009. Marine ice sheet dynamics: Hysteresis and neutral equilibrium. J. Geophys. Res. 114 (F3).

Dutrieux, P., De Rydt, J., Jenkins, A., Holland, P. R., Ha, H. K., Lee, S. H., Steig, E. J., Ding, Q., Abrahamsen, E. P., Schröder, M., 2014. Strong sensitivity of Pine Island ice-shelf melting to climatic variability. Science 343 (6167), 174-178.

Favier, L., Durand, G., Cornford, S. L., Gudmundsson, G. H., Gagliardini, O., Gillet-Chaulet, F., Zwinger, T., Payne, A. J., Le Brocq, A. M., 2014. Retreat of Pine Island Glacier controlled by marine ice-sheet instability. Nature Climate Change 4 (2), 117-121.

Furevik, T., Foldvik, A., 1996. Stability at M2 critical latitude in the Barents Sea. J. Geophys. Res. 101 (C4), 8823-8837.

Galton-Fenzi, B. K., Hunter, J. R., Coleman, R., Marsland, S. J., Warner, R. C., 2012. Modeling the basal melting and marine ice accretion of the Amery Ice Shelf. J. Geophys. Res. 117 (C9).

Griffies, S. M., Biastoch, A., Böning, C., Bryan, F., Danabasoglu, G., Chassignet, E. P., England, M. H., Gerdes, R., Haak, H., Hallberg, R. W., et al., 2009. Coordinated ocean-ice reference experiments (COREs). Ocean Modell. 26 (1), 1-46.

Gwyther, D. E., Cougnon, E. A., Galton-Fenzi, B. K., Roberts, J. L., Hunter, J. R., Dinniman, M. S., 2016. Modelling the response of ice shelf basal melting to different ocean cavity environmental regimes. Annals of Glaciology, $1-11$.

Hattermann, T., Smedsrud, L. H., Nøst, O. A., Lilly, J. M., Galton-Fenzi, B. K., 2014. Eddy-resolving simulations of the Fimbul Ice Shelf cavity circulation: Basal melting and exchange with open ocean. Ocean Modelling $82,28-44$.

Hemer, M. A., Hunter, J. R., Coleman, R., 2006. Barotropic tides beneath the Amery Ice Shelf. J. Geophys. Res. 111 (C11). 
Heywood, K. J., Locarnini, R. A., Frew, R. D., Dennis, P. F., King, B. A., 1998. Transport and water masses of the Antarctic Slope Front system in the eastern Weddell Sea. Antarctic Research Series 75, 203-214.

Holland, P. R., Jenkins, A., Holland, D. M., 2008. The response of ice shelf basal melting to variations in ocean temperature. J. Climate 21 (11), 25582572 .

Holloway, G., Proshutinsky, A., 2007. Role of tides in Arctic ocean/ice climate. J. Geophys. Res. 112 (C4).

Jacobs, S., Jenkins, A., Hellmer, H., Giulivi, C., Nitsche, F., Huber, B., Guerrero, R., 2012. The Amundsen Sea and the Antarctic ice sheet. Oceanography $25(3), 154-163$.

Jenkins, A., 1999. The impact of melting ice on ocean waters. J. Phys. Oceanogr. 29 (9), 2370-2381.

Jenkins, A., Nicholls, K. W., Corr, H. F. J., 2010. Observation and parameterization of ablation at the base of Ronne Ice Shelf, Antarctica. J. Phys. Oceanogr. 40 (10), 2298-2312.

Joughin, I., Smith, B. E., Medley, B., 2014. Marine ice sheet collapse potentially under way for the Thwaites Glacier Basin, West Antarctica. Science 344 (6185), 735-738.

Jourdain, N. C., Mathiot, P., Merino, N., Durand, G., Le Sommer, J., Spence, P., Dutrieux, P., Madec, G., 2017. Ocean circulation and sea-ice thinning induced by melting ice shelves in the Amundsen Sea. J. Geophys. Res. Oceans 122 (3), 2550-2573.

Large, W. G., Yeager, S. G., 2009. The global climatology of an interannually varying air-sea flux data set. Clim. Dynam. 33 (2-3), 341-364.

Leclair, M., Madec, G., 2011. z-Coordinate, an Arbitrary LagrangianEulerian coordinate separating high and low frequency motions. Ocean Modelling 37 (3-4), 139-152.

Lee, H.-C., Rosati, A., Spelman, M. J., 2006. Barotropic tidal mixing effects in a coupled climate model: Oceanic conditions in the northern Atlantic. Ocean Model. 11 (3), 464-477. 
Longuet-Higgins, M. S., 1969. On the transport of mass by time-varying ocean currents 16 (5), 431-447.

Losch, M., 2008. Modeling ice shelf cavities in az coordinate ocean general circulation model. J. Geophys. Res. 113 (C8).

Lyard, F., Lefevre, F., Letellier, T., Francis, O., 2006. Modelling the global ocean tides: modern insights from FES2004. Ocean Dynamics 56 (5-6), $394-415$.

MacAyeal, D. R., 1984a. Numerical simulations of the Ross Sea tides. J. Geophys. Res. 89 (C1), 607-615.

MacAyeal, D. R., 1984b. Thermohaline circulation below the Ross Ice Shelf: A consequence of tidally induced vertical mixing and basal melting. J. Geophys. Res. 89 (C1), 597-606.

Mack, S. L., Dinniman, M. S., McGillicuddy Jr, D. J., Sedwick, P. N., Klinck, J. M., 2017. Dissolved iron transport pathways in the Ross Sea: Influence of tides and horizontal resolution in a regional ocean model. Journal of Marine Systems 166, 73-86.

Madec, G., NEMO-team, 2016. NEMO ocean engine, version 3.6 stable, Note du Pôle de modélisation de l'Institut Pierre-Simon Laplace No 27, ISSN No 1288-1619. Tech. rep., IPSL, France.

Makinson, K., Holland, P. R., Jenkins, A., Nicholls, K. W., Holland, D. M., 2011. Influence of tides on melting and freezing beneath Filchner-Ronne Ice Shelf, Antarctica. Geophys. Res. Lett. 38 (6).

Makinson, K., Nicholls, K. W., 1999. Modeling tidal currents beneath Filchner-Ronne Ice Shelf and on the adjacent continental shelf: Their effect on mixing and transport. J. Geophys. Res. 104 (C6), 13449-13465.

Maraldi, C., Chanut, J., Levier, B., Ayoub, N., De Mey, P., Reffray, G., Lyard, F., Cailleau, S., Drévillon, M., Fanjul, E., et al., 2013. NEMO on the shelf: assessment of the Iberia-Biscay-Ireland configuration. Ocean Science 9, 745-771.

Mathiot, P., Goosse, H., Fichefet, T., Barnier, B., Gallée, H., 2011. Modelling the seasonal variability of the Antarctic Slope Current. Ocean Science 7 (4), $445-532$. 
Mathiot, P., Jenkins, A., Harris, C., Madec, G., 2017. Explicit and parametrised representation of under ice shelf seas in $\mathrm{az}^{*}$ coordinate ocean model NEMO 3.6. Geoscientific Model Development 10 (7), 2849-2874.

McMillan, M., Shepherd, A., Nienow, P., Leeson, A., 2011. Tide model accuracy in the Amundsen Sea, Antarctica, from radar interferometry observations of ice shelf motion. J. Geophys. Res. 116 (C11).

McPhee, M. G., Morison, J. H., Nilsen, F., 2008. Revisiting heat and salt exchange at the ice-ocean interface: Ocean flux and modeling considerations. J. Geophys. Res. 113 (C6).

Middleton, J. H., Foster, T. D., Foldvik, A., 1987. Diurnal shelf waves in the southern Weddell Sea. J. Phys. Oceanogr. 17 (6), 784-791.

Millan, R., Rignot, E., Bernier, V., Morlighem, M., Dutrieux, P., 2017. Bathymetry of the Amundsen Sea Embayment sector of West Antarctica from Operation IceBridge gravity and other data. Geophys. Res. Lett. 44 (3), 1360-1368.

Mouginot, J., Rignot, E., Scheuchl, B., 2014. Sustained increase in ice discharge from the Amundsen Sea Embayment, West Antarctica, from 1973 to 2013. Geophys. Res. Lett. 41 (5), 1576-1584.

Mueller, R. D., Hattermann, T., Howard, S. L., Padman, L., 2018. Tidal influences on a future evolution of the Filchner-Ronne Ice Shelf cavity in the Weddell Sea, Antarctica. The Cryosphere 12 (2), 453.

Mueller, R. D., Padman, L., Dinniman, M. S., Erofeeva, S. Y., Fricker, H. A., King, M. A., 2012. Impact of tide-topography interactions on basal melting of Larsen C Ice Shelf, Antarctica. J. Geophys. Res. 117 (C5).

Müller, M., 2013. On the space-and time-dependence of barotropic-tobaroclinic tidal energy conversion. Ocean Model. 72, 242-252.

Olbers, D., Eden, C., 2013. A global model for the diapycnal diffusivity induced by internal gravity waves. J. Phys. Oceanogr. 43 (8), 1759-1779.

Padman, L., Erofeeva, S., Joughin, I., 2003. Tides of the Ross Sea and Ross Ice Shelf cavity. Antarctic Science 15 (01), 31-40. 
Padman, L., Fricker, H. A., Coleman, R., Howard, S., Erofeeva, L., 2002. A new tide model for the Antarctic ice shelves and seas. Annals of Glaciology 34 (1), 247-254.

Padman, L., Howard, S. L., Orsi, A. H., Muench, R. D., 2009. Tides of the northwestern Ross Sea and their impact on dense outflows of Antarctic Bottom Water. Deep Sea Research Part II: Topical Studies in Oceanography 56 (13), 818-834.

Padman, L., Kottmeier, C., 2000. High-frequency ice motion and divergence in the Weddell Sea. J. Geophys. Res. 105 (C2), 3379-3400.

Padman, L., Siegfried, M. R., Fricker, H. A., 2018. Ocean Tide Influences on the Antarctic and Greenland Ice Sheets. Reviews of Geophysics 56, 1-43.

Richet, O., Muller, C., Chomaz, J.-M., 2017. Impact of a Mean Current on the Internal Tide Energy Dissipation at the Critical Latitude. J. Phys. Oceanogr. 47 (6), 1457-1472.

Robertson, R., 2013. Tidally induced increases in melting of Amundsen Sea ice shelves. J. Geophys. Res. 118 (6), 3138-3145.

Rousset, C., Vancoppenolle, M., Madec, G., Fichefet, T., Flavoni, S., Barthélemy, A., Benshila, R., Chanut, J., Lévy, C., Masson, S., et al., 2015. The Louvain-La-Neuve sea ice model LIM3.6: global and regional capabilities. Geoscientific Model Development 8 (10), 2991-3005.

Savage, A. C., Arbic, B. K., Alford, M. H., Ansong, J. K., Farrar, J. T., Menemenlis, D., O’Rourke, A. K., Richman, J. G., Shriver, J. F., Voet, G., et al., 2017. Spectral decomposition of internal gravity wave sea surface height in global models. J. Geophys. Res. 122 (10), 7803-7821.

Schaffer, J., Timmermann, R., Arndt, J. E., Kristensen, S. S., Mayer, C., Morlighem, M., Steinhage, D., 2016. A global high-resolution data set of ice sheet topography, cavity geometry and ocean bathymetry. Earth System Science Data.

Scheduikat, M., Olbers, D. J., 1990. A one-dimensional mixed layer model beneath the Ross Ice Shelf with tidally induced vertical mixing. Antarctic Science 2 (01), 29-42. 
Schoof, C., 2007. Ice sheet grounding line dynamics: Steady states, stability, and hysteresis. J. Geophys. Res. 112 (F3).

Schureman, P., 1958. Manual of harmonic analysis and prediction of tides. No. 98. US Government Printing Office.

Simmons, H. L., Jayne, S. R., St-Laurent, L. C., Weaver, A. J., 2004. Tidally driven mixing in a numerical model of the ocean general circulation. Ocean Modelling 6 (3), 245-263.

Spence, P., Griffies, S. M., England, M. H., Hogg, A. M., Saenko, O. A., Jourdain, N. C., 2014. Rapid subsurface warming and circulation changes of Antarctic coastal waters by poleward shifting winds. Geophys. Res. Lett. 41 (13), 4601-4610.

Stewart, A. L., Klocker, A., Menemenlis, D., 2018. Circum-Antarctic Shoreward Heat Transport Derived From an Eddy-and Tide-Resolving Simulation. Geophys. Res. Lett.

Timmermann, R., Beckmann, A., Hellmer, H. H., 2002. Simulations of iceocean dynamics in the Weddell Sea 1. Model configuration and validation. J. Geophys. Res. 107 (C3).

Turner, J., Orr, A., Gudmundsson, G. H., Jenkins, A., Bingham, R. G., Hillenbrand, C.-D., Bracegirdle, T. J., 2017. Atmosphere-ocean-ice interactions in the Amundsen Sea Embayment, West Antarctica. Reviews of Geophysics 55 (1), 235-276.

Wang, Q., Danilov, S., Hellmer, H., Sidorenko, D., Schroeter, J., Jung, T., 2013. Enhanced cross-shelf exchange by tides in the western Ross Sea. Geophys. Res. Lett. 40 (21), 5735-5739.

Weertman, J., 1974. Stability of the junction of an ice sheet and an ice shelf. J. Glaciol. 13, 3-11.

Zimmerman, J. T. F., 1979. On the Euler-Lagrange transformation and the Stokes' drift in the presence of oscillatory and residual currents. Deep Sea Research Part A. Oceanographic Research Papers 26 (5), 505-520. 


\begin{tabular}{|l|c|c|l|l|}
\hline Simulation & $\begin{array}{c}\text { Sea } \\
\text { Ice }\end{array}$ & $\begin{array}{c}\text { Atm. } \\
\text { For. }\end{array}$ & $\begin{array}{l}\text { Ice shelf } \\
\text { melt }\end{array}$ & $\begin{array}{l}\text { Lateral } \\
\text { boundaries }\end{array}$ \\
\hline BTP-07 & - & - & zero & $T_{0}, S_{0}$, tides $(7$ har. $)$ \\
REF & LIM & CORE & 3-equation & MOM025, no tides \\
TIDE-M2 & LIM & CORE & 3-equation & MOM025, tides (1 har.) \\
TIDE-04 & LIM & CORE & 3-equation & MOM025, tides (4 har.) \\
TIDE-18 & LIM & CORE & 3-equation & MOM025, tides (18 har.) \\
Utide-UNIF & LIM & CORE & 3-equ. w. uniform $u_{\text {tide }}^{2}(1$ value) & MOM025, no tides \\
Utide-PERISF & LIM & CORE & 3-equ. w. uniform $u_{\text {tide }}^{2}($ per ice shelf $)$ & MOM025, no tides \\
Utide $(x, y)$ & LIM & CORE & 3-equ. w. $u_{\text {tide }}^{2}(x, y)$ & MOM025, no tides \\
0.777Utide(x,y) & LIM & CORE & 3-equ. w. $\left(0.777 \times u_{\text {tide }}(x, y)\right)^{2}$ & MOM025, no tides \\
\hline
\end{tabular}

Table 1: List of the nine 7-year AMU12.L75 simulations used in this paper. "3-equation" means that the square friction velocity involved in the three melt equations is directly proportional to the square TBL velocity, with no additional background RMS velocity unless specified. The "MOM025" lateral boundaries refer to 5-day temperature, salinity, velocity, sea-ice concentration and thickness prescribed from the $0.25^{\circ} \mathrm{MOM}$ simulation produced by Spence et al. (2014).

\begin{tabular}{|l|l|l|l|}
\hline $\begin{array}{l}\text { Ice } \\
\text { Shelf }\end{array}$ & $\begin{array}{l}\text { tidal residual } \\
\text { circulation } \\
(\mathrm{mSv})\end{array}$ & $\begin{array}{l}\text { circulation } \mathrm{w} . \\
18 \text { tidal harm. } \\
(\mathrm{mSv})\end{array}$ & $\begin{array}{l}\text { circulation w. } \\
\text { no tide } \\
(\mathrm{mSv})\end{array}$ \\
\hline Getz & 24 & 320 & 278 \\
Dotson & 5 & 247 & 241 \\
Crosson & 3 & 58 & 65 \\
Thwaites & 5 & 313 & 317 \\
Pine Island & 2 & 299 & 290 \\
Cosgrove & 1 & 48 & 41 \\
Abbot & 20 & 251 & 179 \\
\hline
\end{tabular}

Table 2: Barotropic transport within each cavity, calculated as the maximum amplitude (maximum minus minimum) of the barotropic stream function under the ice-shelf. These numbers are calculated from averages over the $3^{\text {rd }}$ year of the BTP-07 simulation $\left(2^{\text {nd }}\right.$ column $)$ and over the $7^{\text {th }}$ year of the TIDE-18 ( $3^{\text {rd }}$ column $)$ and REF ( $4^{\text {th }}$ column $)$ simulations. 


\begin{tabular}{|l|r|r|r|r|c|c|}
\hline $\begin{array}{l}\text { Ice } \\
\text { Shelf }\end{array}$ & $\begin{array}{r}\text { Melt with } \\
\text { no tides }\end{array}$ & Melt with $\mathrm{M}_{2}$ & $\begin{array}{r}\text { Melt with } \mathrm{M}_{2}, \\
\mathrm{~S}_{2}, \mathrm{~K}_{1}, \mathrm{O}_{1}\end{array}$ & $\begin{array}{r}\text { Melt with 18 } \\
\text { harmonics }\end{array}$ & $\begin{array}{c}u_{\text {tide }} \\
\text { (RMS) }\end{array}$ & $\begin{array}{c}u_{\text {tide }} \\
\text { (harm. })\end{array}$ \\
\hline Getz & 277.6 & $282.5(+1.8 \%)$ & $305.5(+10 \%)$ & $309.0(+11 \%)$ & 4.9 & 4.3 \\
Dotson & 25.0 & $26.4(+5.6 \%)$ & $31.7(+27 \%)$ & $32.6(+30 \%)$ & 6.1 & 3.1 \\
Crosson & 8.0 & $8.4(+5.0 \%)$ & $9.8(+22 \%)$ & $9.8(+22 \%)$ & 6.5 & 5.7 \\
Thwaites & 70.4 & $71.5(+1.6 \%)$ & $74.9(+6.4 \%)$ & $75.9(+7.8 \%)$ & 2.3 & 0.9 \\
Pine Island & 124.3 & $124.5(+0.2 \%)$ & $124.8(+0.4 \%)$ & $125.9(+1.3 \%)$ & 1.8 & 1.3 \\
Cosgrove & 20.2 & $21.2(+4.9 \%)$ & $25.4(+26 \%)$ & $27.0(+34 \%)$ & 4.9 & 3.3 \\
Abbot & 94.7 & $100.8(+6.4 \%)$ & $128.8(+36 \%)$ & $131.4(+39 \%)$ & 5.6 & 3.6 \\
\hline
\end{tabular}

Table 3: Mean melt rates in the simulated ice shelf cavities $\left(\mathrm{Gt}_{\mathrm{yr}}{ }^{-1}\right)$. Increase relative to the first column is shown in brackets. The two last columns show the tidal TBL velocity in each individual cavity (in cm.s ${ }^{-1}$ ) from the simulation with 18 tidal constituents, either deduced from a time-RMS difference between the simulation with tides and the one with no tides (RMS diff.) or from a harmonic analysis of the TBL velocity in the simulation with tides (Eq. 7).

\begin{tabular}{|l|l|}
\hline$\Gamma_{\mathrm{T}}$ & $2.21 \times 10^{-3}$ \\
$C_{d}$ & $1.00 \times 10^{-3}$ \\
$\alpha$ & 0.777 \\
$A_{0}$ & 0.656 \\
$U_{0}$ & $0.003 \mathrm{~m} . \mathrm{s}^{-1}$ \\
\hline
\end{tabular}

Table 4: Values of the coefficients used in Eq. (9). 

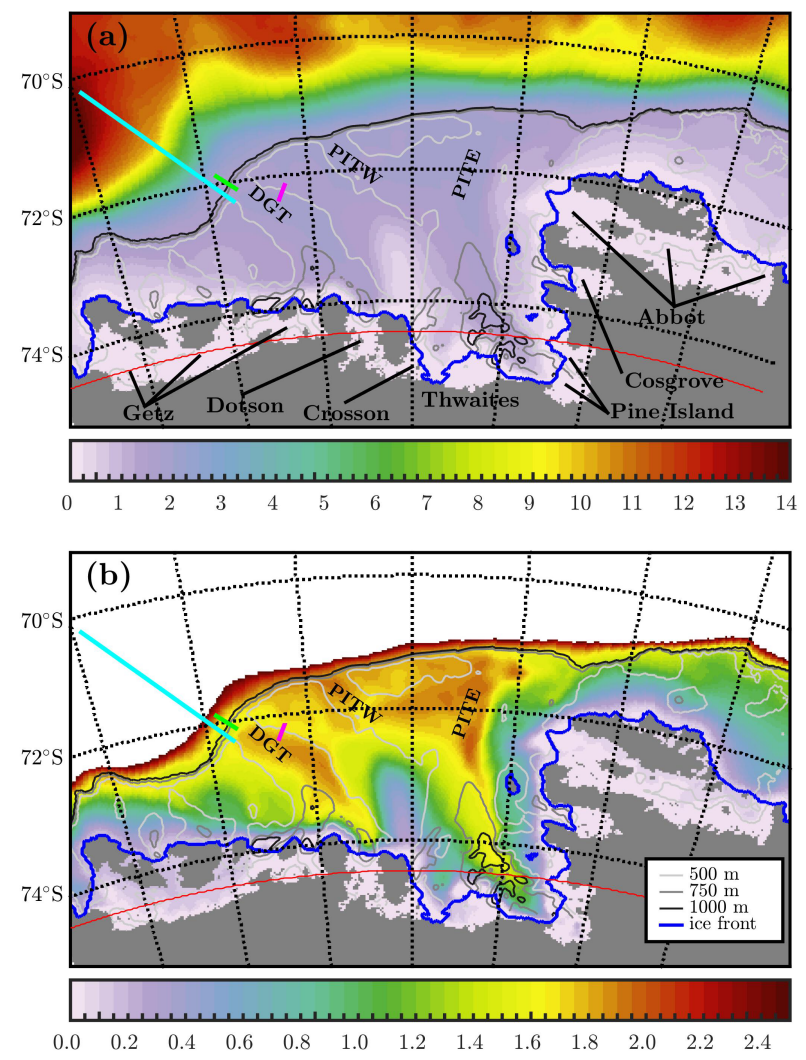

Figure 1: (a) Mean barotropic stream function $(\mathrm{Sv})$ in the reference simulation (REF). Maxima indicate clockwise rotation and minima indicate anti-clockwise rotation. (b) same as (a) but with finer color range. Ice shelf names located within the domain are indicated, as well as DGT (Dotson-Getz Trough), PITW (Pine Island Trough - West) and PITE (Pine Island Trough - East). Are also shown: the $\mathrm{M}_{2}$ critical latitude (red), the bathymetry on the continental shelf (grey contours), and the land ice terminus (blue). The grounded ice is in grey. The barotropic transports across the cyan, green and magenta sections are 11.7 Sv, 0.49 Sv and 0.13 Sv respectively. 

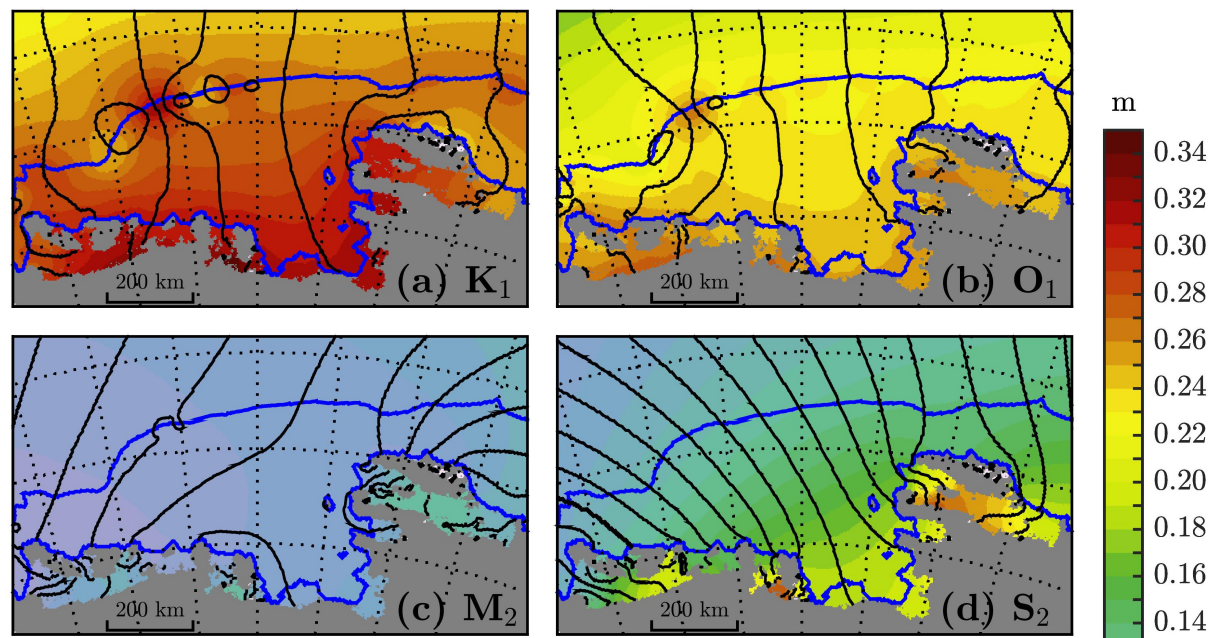

0.26

0.24

0.22

0.20

0.18

0.16

0.14
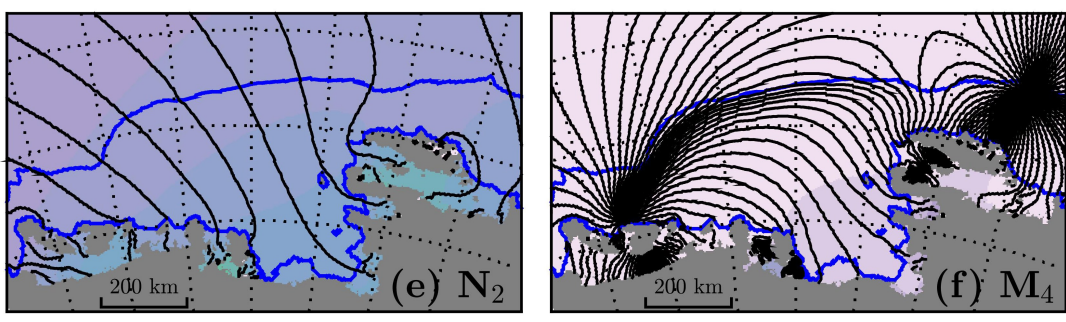

0.12

0.10

0.08

0.06

0.04

0.02

0.00

Figure 2: Amplitude (shaded) and phase (thin black, contour every $5^{\circ}$ ) of six SSH harmonics in the pseudo-barotropic experiment (harmonic analysis over the six first months of the third simulation year). Grounded ice is in gray, and the thick blue contours represent the ice-sheet margin and the $1500 \mathrm{~m}$ isobath (indicating the location of the continental shelf break). Dotted lines are latitude (every $2^{\circ}$ ) and longitude (every $5^{\circ}$ ). 

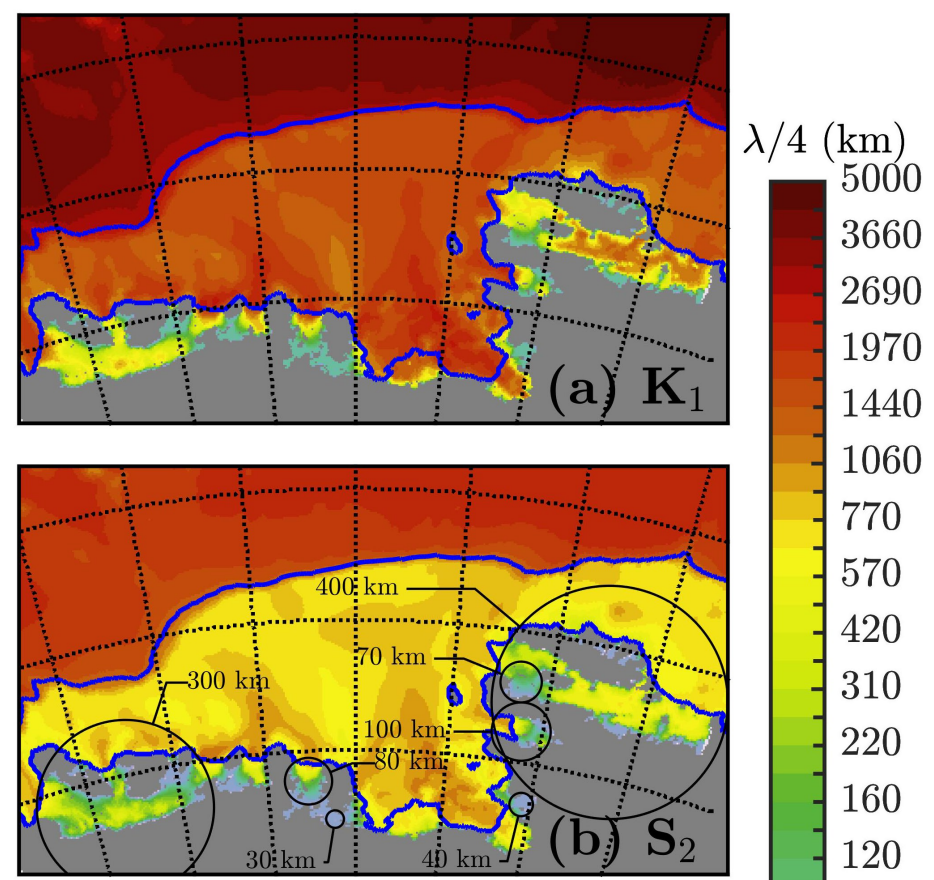

1060

770

570

420

310

220

160

120

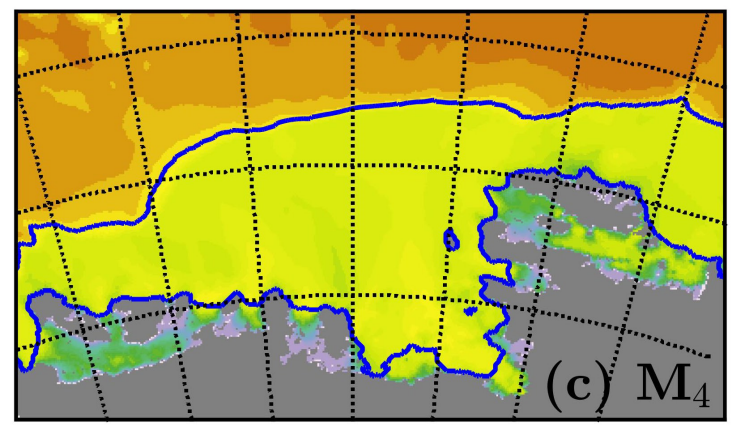

88

65

47

35

25

19

14

10

Figure 3: Quarter wavelength estimated under the shallow water approximation for (a) $\mathrm{K}_{1}$, (b) $\mathrm{S}_{2}$ and (c) $\mathrm{M}_{4}$. The circles indicate typical ice-shelf and bay sizes on the map. The blue lines show the land ice terminus and the continental shelf break (1500 $\mathrm{m}$ isoline). 

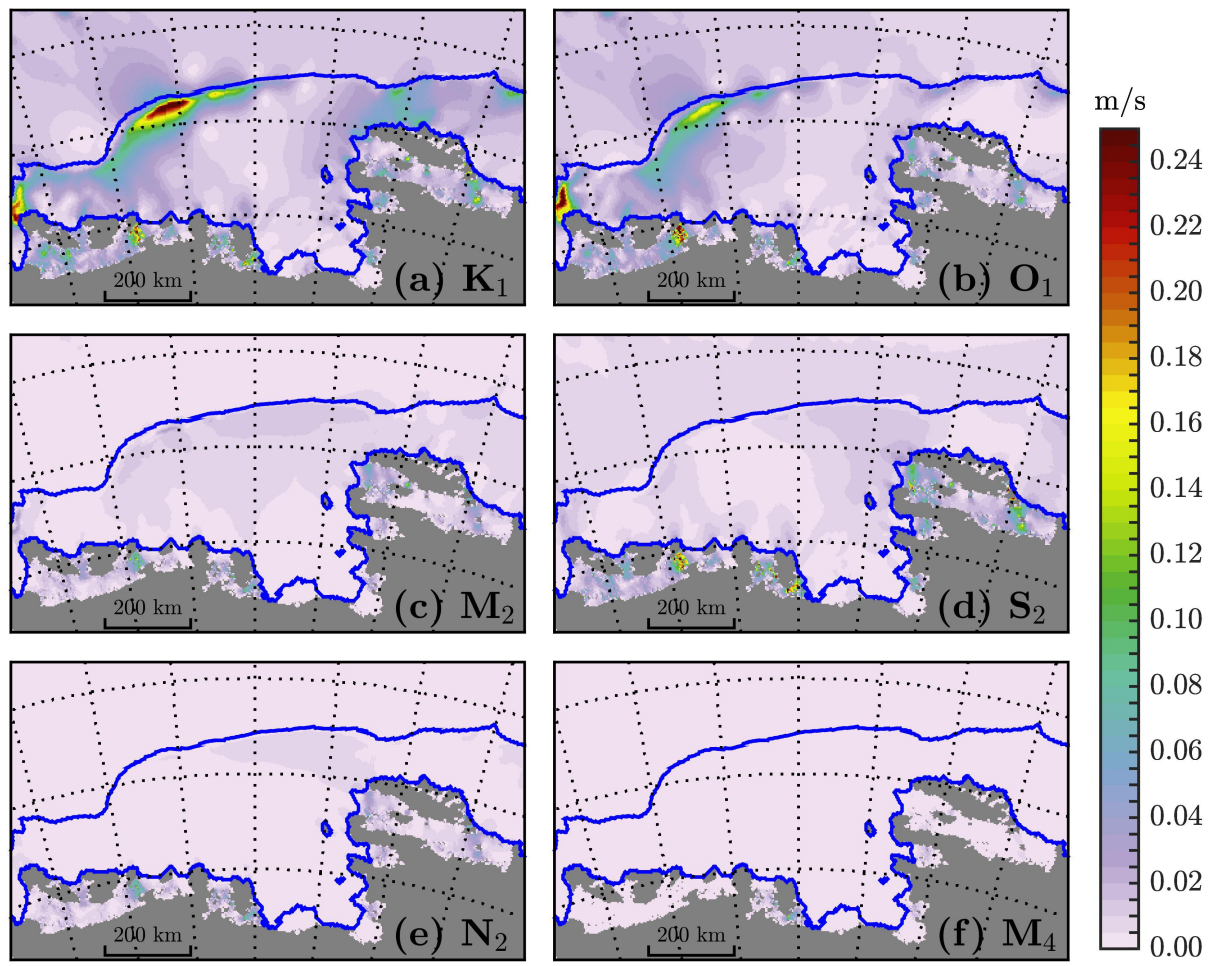

Figure 4: Major semi-axis of the tidal ellipse related to six barotropic-velocity harmonics (shaded) in the pseudo-barotropic experiment (harmonic analysis over the six first months of the third simulation year). Grounded ice is in gray, and the thick blue contours represent the ice-sheet margin and the $1500 \mathrm{~m}$ isobath (indicating the location of the continental shelf break). Dotted lines are latitude (every $2^{\circ}$ ) and longitude (every $5^{\circ}$ ). 

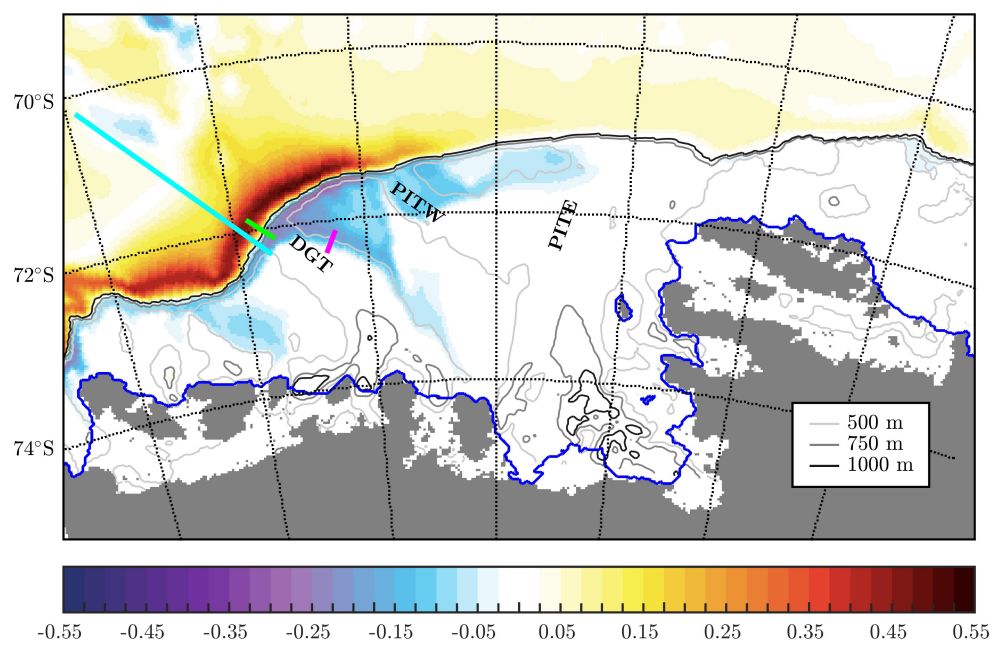

Figure 5: Residual tidal circulation, calculated as the annual mean barotropic stream function $(\mathrm{Sv})$ in the BTP-07 simulation. Maxima indicate clockwise rotation and minima indicate anti-clockwise rotation. The grey contours show the bathymetry on the continental shelf, and the blue contour indicates the land ice temrinus. The grounded ice is in grey. The barotropic transports across the cyan, green and magenta sections are $0.12 \mathrm{~Sv}$, $0.70 \mathrm{~Sv}$ and $0.17 \mathrm{~Sv}$ respectively. 


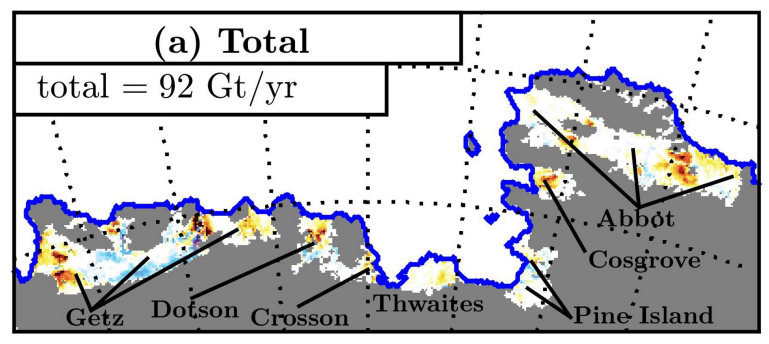

$\mathrm{m} / \mathrm{yr}$
20.0
18.0
16.0
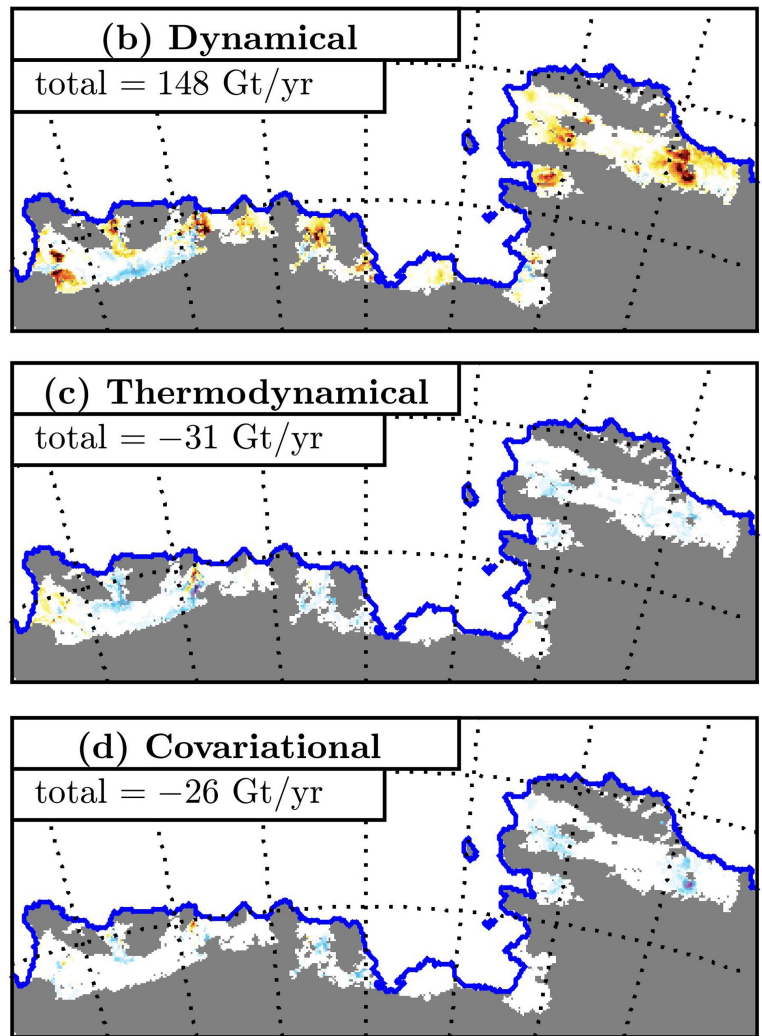

Figure 6: (a) Change in melt rate explained by the presence of 18 tidal harmonics, i.e. $\Delta m$ in Eq. (5). (b-d) Terms of the decomposition of Eq. (5). The numbers in the upper left corners give the total melt anomaly over the domain. 

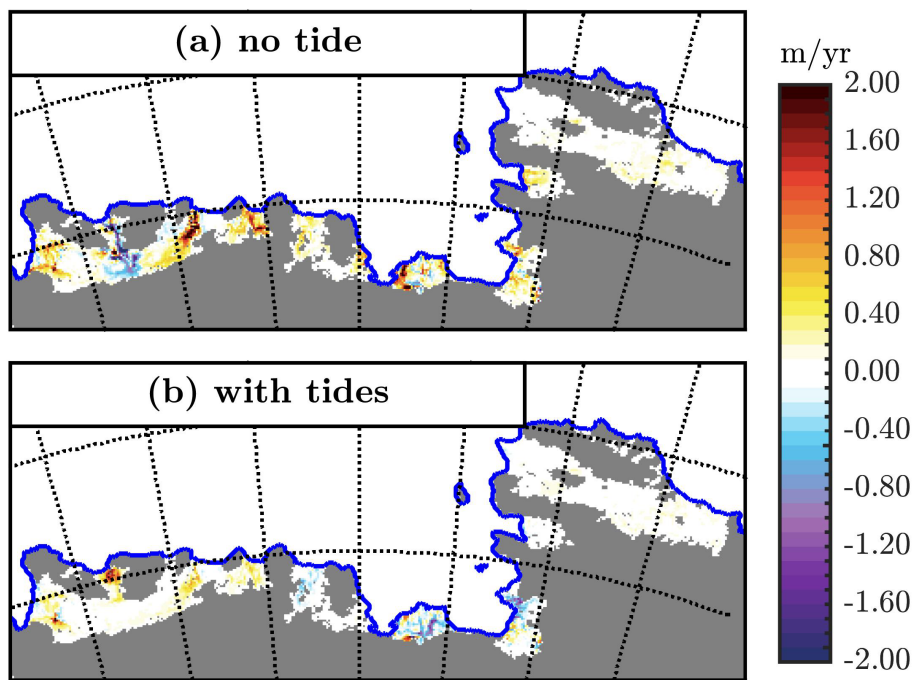

Figure 7: Changes in annual mean melt rates due to a $1^{\circ} \mathrm{S}$ shift of latitudes (i.e. bathymetry and ice drafts are shifted by $1^{\circ} \mathrm{N}$ ) in simulations with (a) no tides, (b) 18 tidal harmonics. The blue contour indicates the land ice terminus and the grounded ice is in grey. Note that the amplitude of the color bar is ten times smaller than in Fig. 6 . 

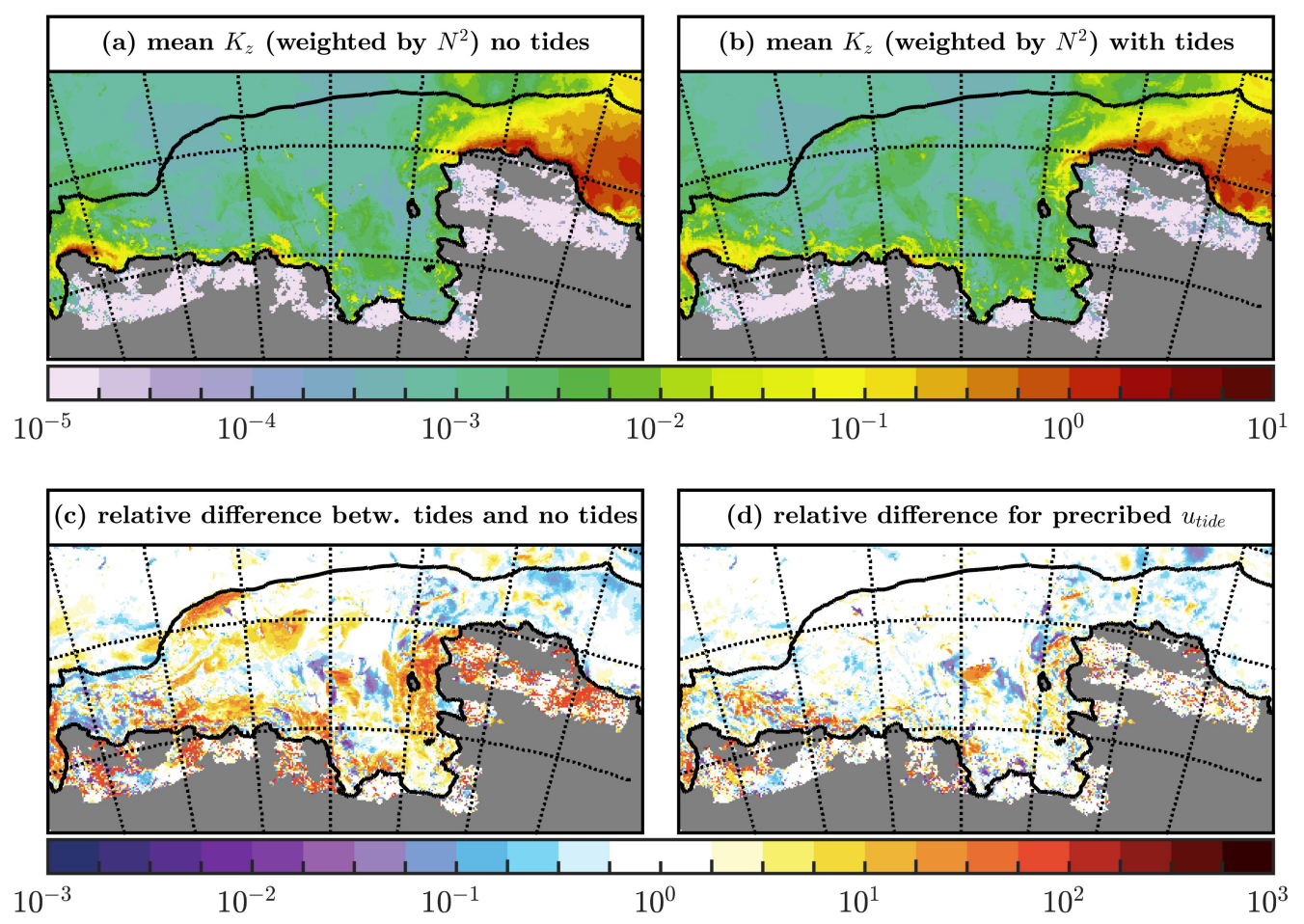

Figure 8: Stratification-weighted depth-mean vertical diffusivity $\left(K_{z}\right.$, in $\left.\mathrm{m}^{2} \cdot \mathrm{s}^{-1}\right)$ in: (a) REF and (b) TIDE-18. (c) relative difference (i.e. difference divided by half sum) between (a) and (b). (d) Same as (c) but with prescribed tidal TBL velocity $(0.777 \operatorname{Utide}(\mathrm{x}, \mathrm{y})$ ) instead of explicit tides. The land ice terminus and the $1500 \mathrm{~m}$ isobath are in black, the grounded ice sheet is in gray. 


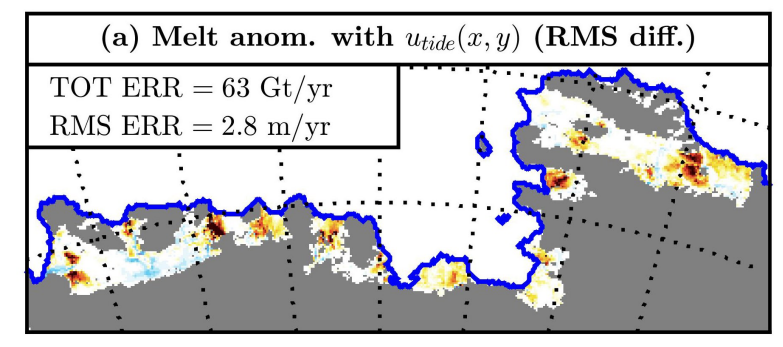

$\mathrm{m} / \mathrm{yr}$

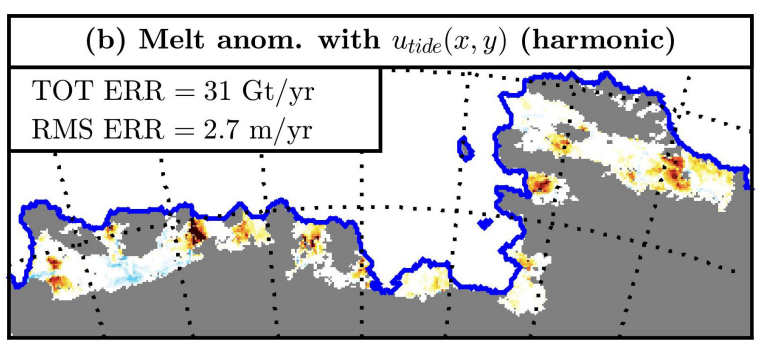

16.0

12.0

8.0

(c) Melt anom. with uniform $u_{\text {tide }}$ (one value)

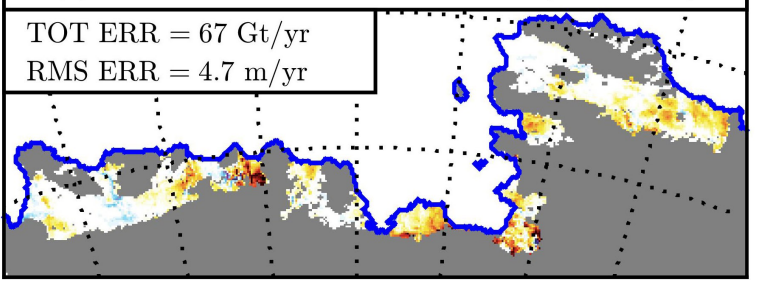

(d) Melt anom. with uniform $u_{\text {tide }}$ (per ice shelf)

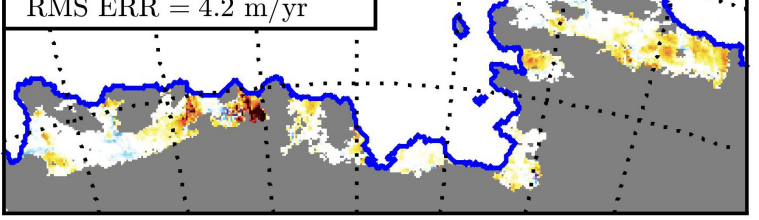

Figure 9: Change in melt rate due to the use of prescribed tidal TBL velocity in the melt equations, with (a) spatially-varying tidal velocity from the RMS difference between TIDE-18 and REF, (b) spatially-varying tidal velocity from a harmonic analysis in TIDE18 , (c) uniform tidal velocity all over the domain, calculated from the RMS of (b) under all the ice shelves, and (d) uniform tidal velocity calculated from the RMS of (b) under each individual ice shelf. The total error and RMS error with respect to the simulation with explicit tides (TIDE-18) are indicated for each panel. 


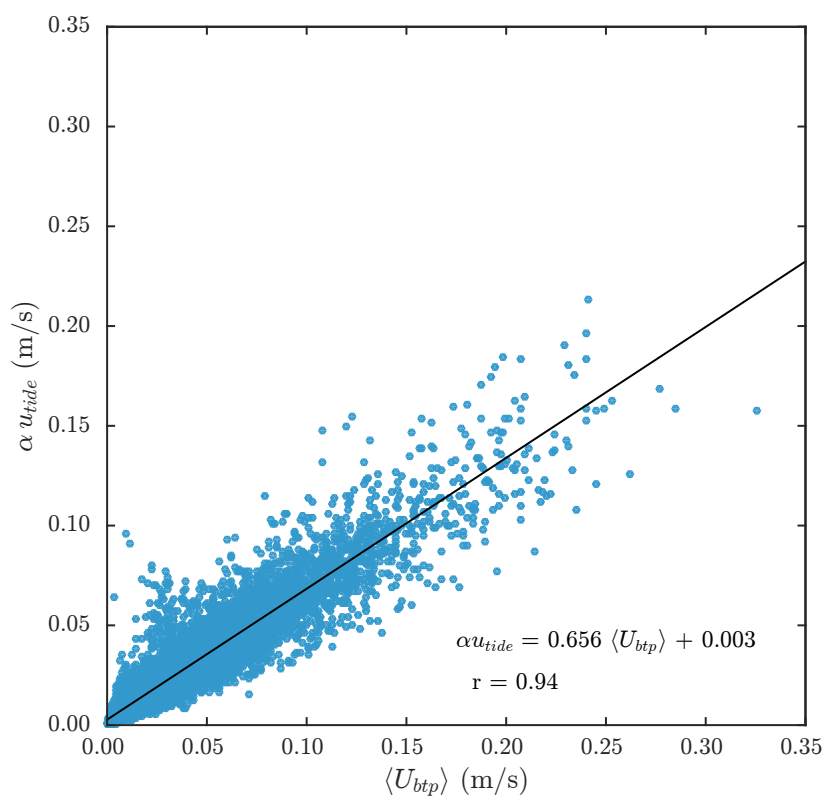

Figure 10: Harmonic tidal TBL velocity (from TIDE-18) versus the root-sum-square barotropic velocity from the harmonic analysis of the BTP-07 simulation as defined in eq. (9). Also indicated are the correlation coefficient (r) and regression coefficients of the least-squares linear fit. 

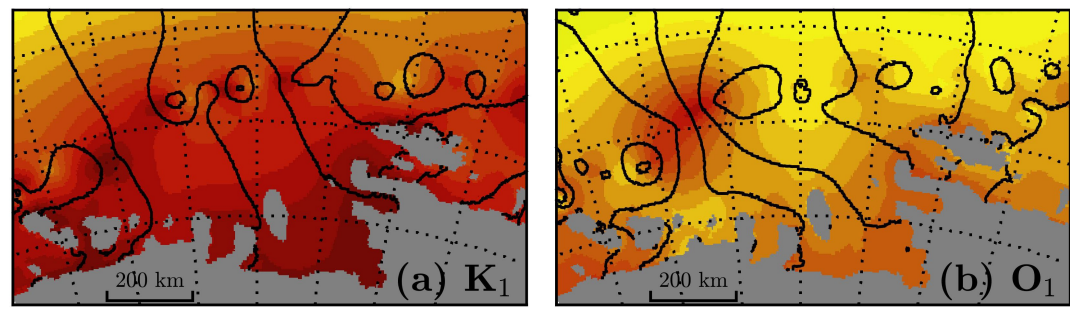

$\mathrm{m}$
0.34
0.32
0.30
-0.28
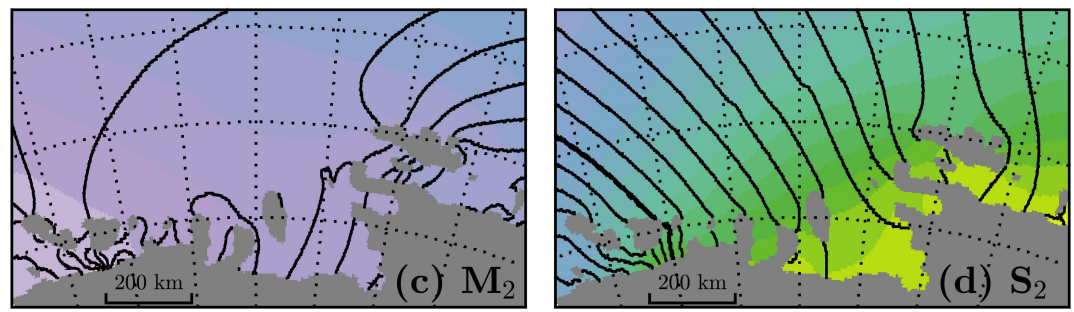

0.26

0.24

$-0.22$

0.20

0.18

0.16

0.14
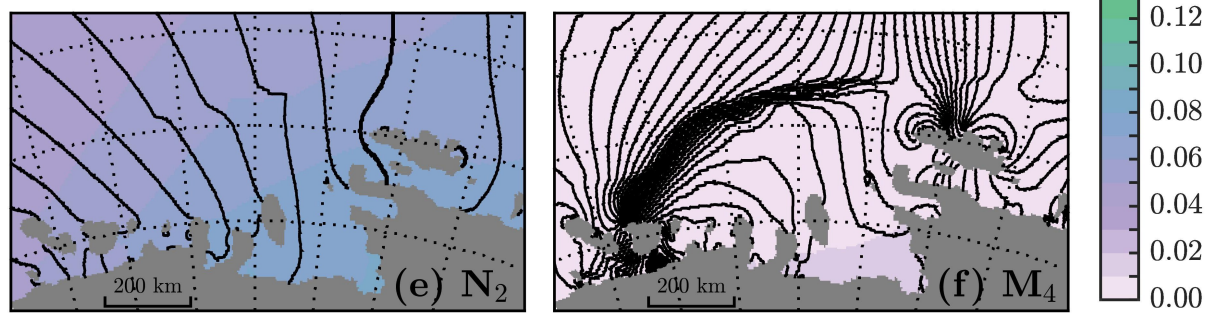

Figure S1: Amplitude (shaded) and phase (thin black, contour every $5^{\circ}$ ) of six SSH harmonics in FES2012. Grounded ice is in gray and dotted lines are latitude (every $2^{\circ}$ ) and longitude (every $5^{\circ}$ ). 

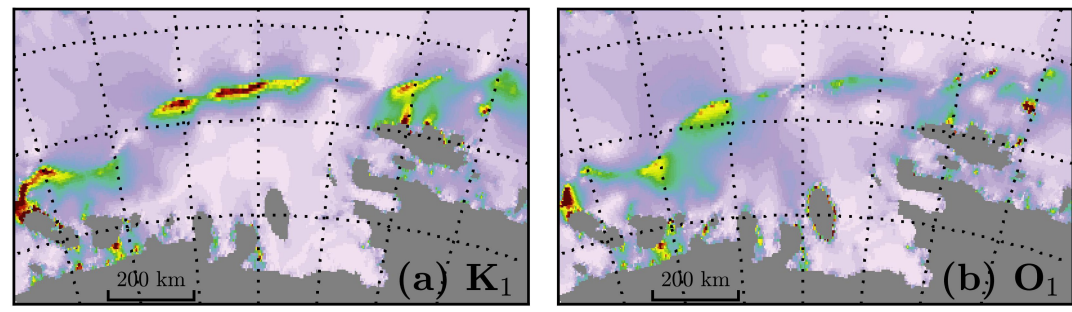

0.24
0.22
$=0.20$
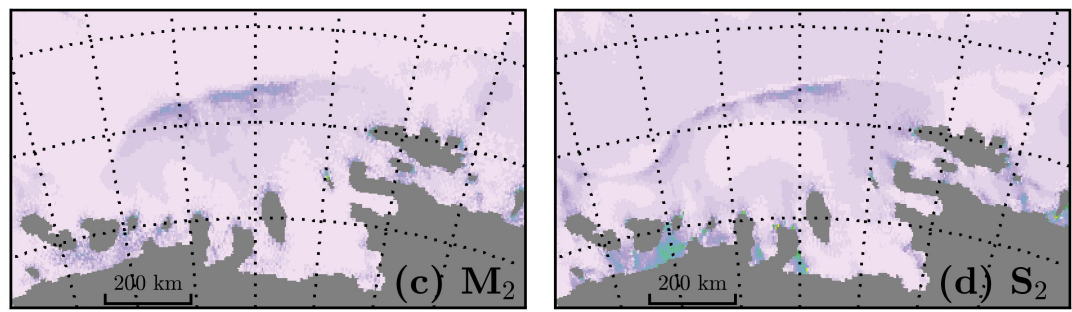

0.18

0.16

0.14

0.12

0.10
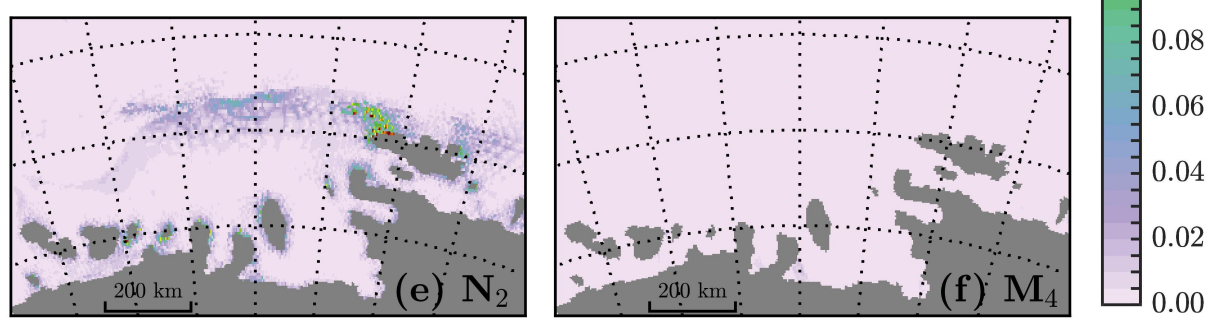

Figure S2: Major semi-axis of the tidal ellipse related to six barotropic-velocity harmonics (shaded) in FES2012. Grounded ice is in gray, and dotted lines are latitude (every $2^{\circ}$ ) and longitude (every $5^{\circ}$ ). 

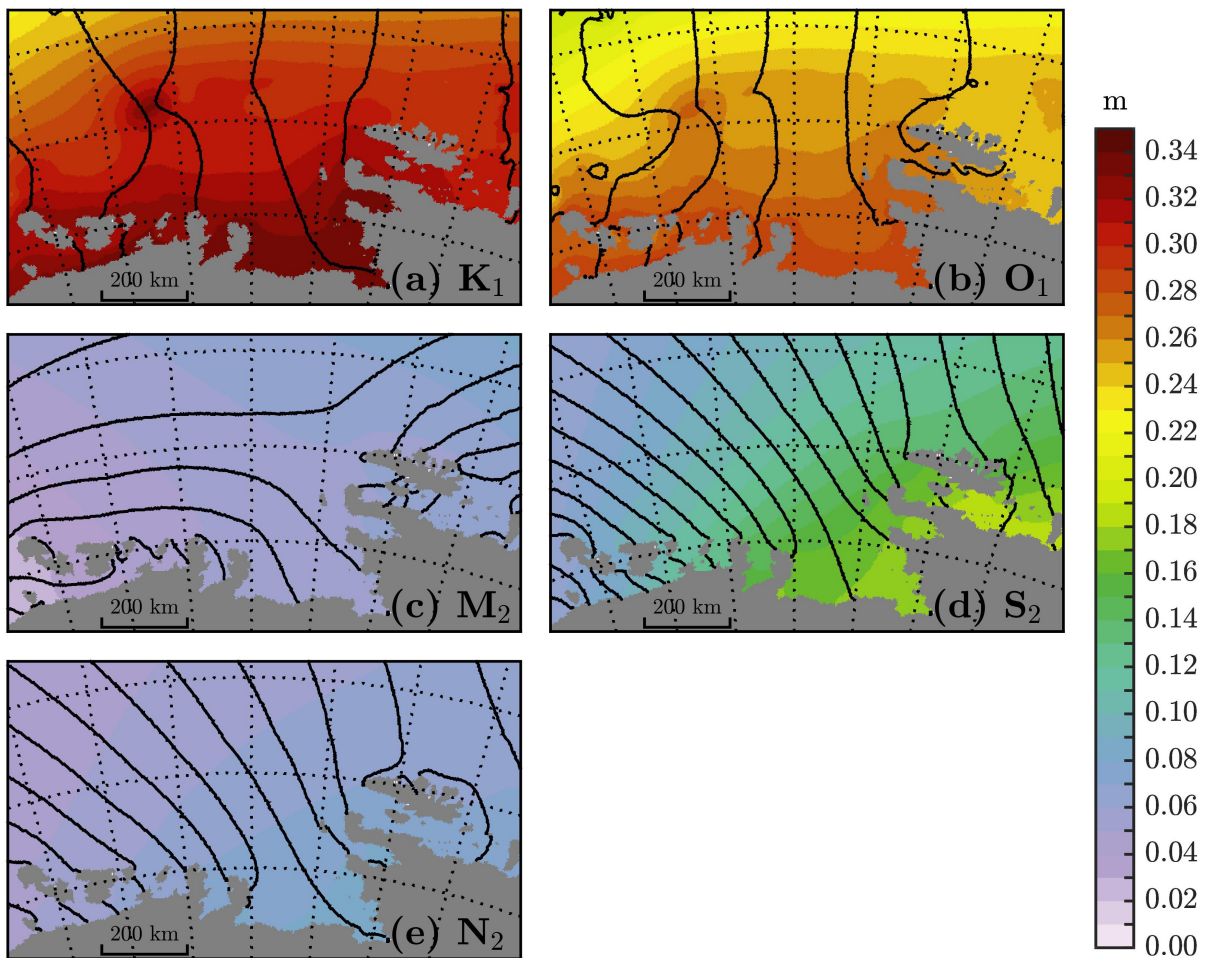

Figure S3: Amplitude (shaded) and phase (thin black, contour every $5^{\circ}$ ) of six SSH harmonics in CATS2008. Grounded ice is in gray and dotted lines are latitude (every $2^{\circ}$ ) and longitude (every $5^{\circ}$ ). 

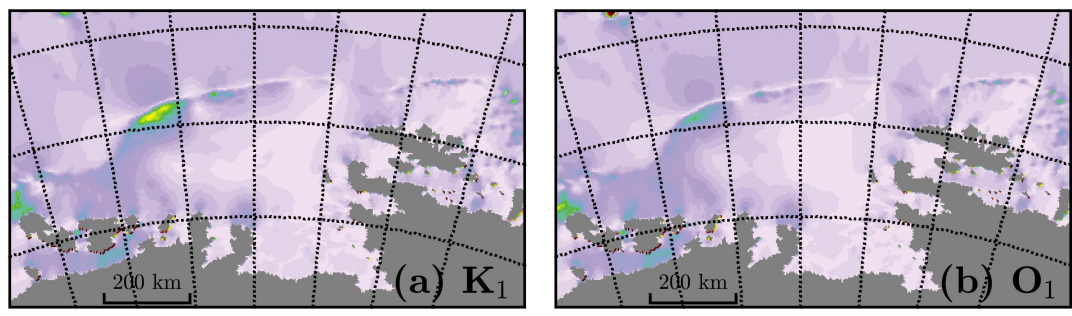

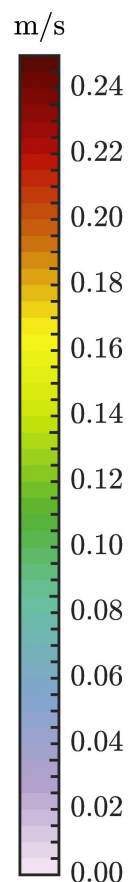
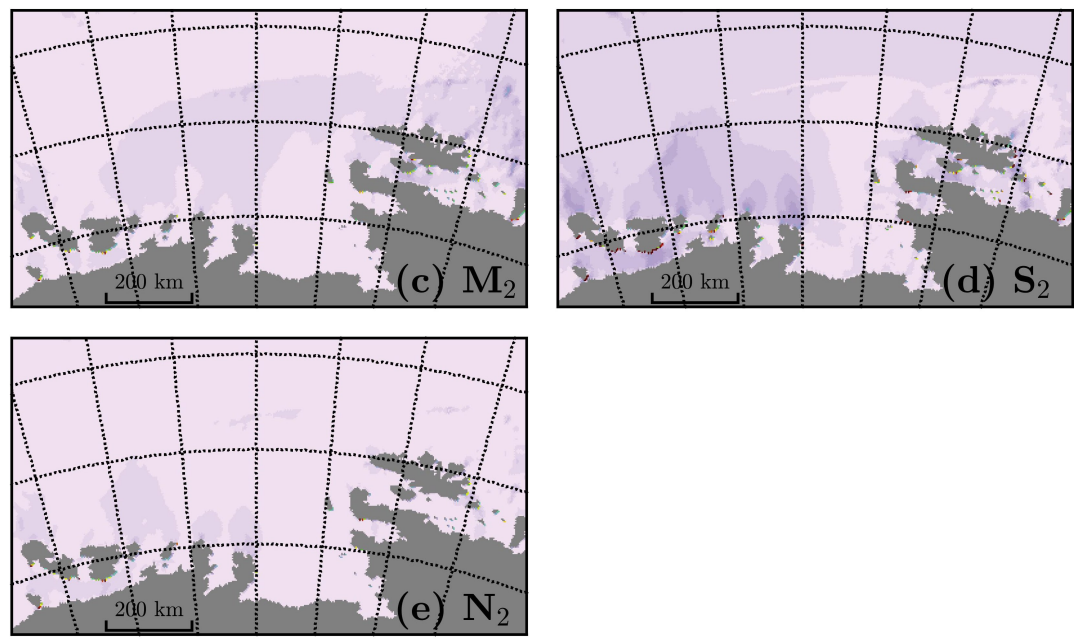

Figure S4: Major semi-axis of the tidal ellipse related to six barotropic-velocity harmonics (shaded) in CATS2008. Grounded ice is in gray, and dotted lines are latitude (every $2^{\circ}$ ) and longitude (every $5^{\circ}$ ). 